\title{
Improving the coexistence of offshore wind farms and shipping: an international comparison of navigational risk assessment processes
}

\author{
Raza Ali Mehdi ${ }^{1}$ (D) - Jens-Uwe Schröder-Hinrichs ${ }^{1}$ • \\ Jeroen van Overloop ${ }^{2} \cdot$ Henrik Nilsson $^{3}$. \\ Jonas Pålsson ${ }^{4}$
}

Received: 25 September 2017 / Accepted: 9 July 2018 / Published online: 23 July 2018

(C) World Maritime University 2018

\begin{abstract}
The continued growth and evolution of the offshore wind industry, and the emergence of other novel marine uses such as wave and tidal generators, have upped the ante for spatial planners, as well as consenting and approval authorities in various coastal states. These stakeholders rely on processes such as navigational risk assessments (NRAs) to balance safety and efficiency requirements and to make optimal decisions over use of space. Given the increasingly complex and crowded seascape, however, there are some apprehensions about potential shortcomings in these NRA processes. There is also some concern that these inadequacies may lead to unsafe or
\end{abstract}

Raza Ali Mehdi

rm@wmu.se

Jens-Uwe Schröder-Hinrichs

jush@wmu.se

Jeroen van Overloop

jeroen.vanoverloop@mobilit.fgov.be

Henrik Nilsson

hn@wmu.se

Jonas Pålsson

jonas.palsson@havochvatten.se

1 Maritime Risk \& System Safety (MaRiSa) Group, World Maritime University (WMU),

Fiskehamnsgatan 1, 21118 Malmö, Sweden

2 Directoraat-generaal Scheepvaart, FOD Mobiliteit en Vervoer, City Atrium, Vooruitgangstraat 56, 1210 Brussels, Belgium

3 Marine Environment Research (MER) Group, WMU, Fiskehamnsgatan 1, 21118 Malmö, Sweden

4 Swedish Agency for Marine and Water Management, Gullbergs Strandgata 15, 40439 Göteborg, Sweden 
inefficient marine spatial use. To understand how NRA processes can be improved further, a literature review is conducted, followed by a survey of respondents who are involved in the planning, consenting and/or approval of offshore wind farms across seven different countries. A summary of the NRA processes in these seven countries is presented, and several shortcomings are identified. Based on the findings of the survey, a list of recommendations is presented to enhance existing NRA processes - and to improve the coexistence of shipping and offshore wind farms (OWFs).

Keywords Offshore wind Planning $\cdot$ Environmental impact $\cdot$ Maritime $\cdot$ Marine $\cdot$ Safety

\section{Introduction}

\subsection{Background}

As the harsh realities of climate change become ever more apparent, there is a noticeable shift towards increased renewable energy generation. One of the most common renewable energy sources is wind power (Engie.be 2017; AP 2018). Significant technological advancements - as well as improved installation, maintenance and decommissioning strategies (Maegaard et al. 2013a, b; Mehdi et al. 2016) - have particularly boosted the reliability of offshore wind farms (OWFs) and driven down the associated levelized cost of energy (LCOE) (Siemens 2014; GWEC 2016). This, along with widespread social acceptance (Henderson et al. 2003; Haggett 2008; Hattam et al. 2015), has also contributed to the increasing popularity of OWFs.

Despite its many advantages, however, offshore wind energy generation is also plagued with a plethora of challenges. For instance, there are still some lingering concerns about the technical challenges, reliability and cost-effectiveness facing OWFs (Ostachowicz et al. 2016). As such, there have been several studies on the life cycle economic (e.g. Blanco 2009; Snyder and Kaiser 2009) and environmental impacts (e.g. Weinzettel et al. 2009; Wang and Sun 2012) of OWFs to address some of the aforementioned concerns.

In addition to the technical and cost-related challenges, further barriers to the continued growth of the offshore wind industry stem from the environmental impact of OWFs. Marine biologists, for instance, carefully scrutinize the impact of OWFs on marine life (e.g. Köller et al. 2006; Degraer and Brabant 2009; Andersson 2011; Bailey et al. 2014; Bray et al. 2016; Verfuss et al. 2016). Similarly, ornithologists are often concerned that OWFs may negatively affect the migration and breeding patterns of various avian species (e.g. Desholm and Kahlert 2005; Dierschke et al. 2006; Hüppop et al. 2006; Degraer and Brabant 2009; Beiersdorf and Radecke 2014; New et al. 2015). Furthermore, there are also other environmental and societal impacts of OWFs - such as the perceptions of coastal communities - that can also be viewed as potential barriers; these topics are covered in works such as those of Devine-Wright (2005), Lacroix and Pioch (2011), Ladenburg (2011) and Chen et al. (2015).

A crucial topic often discussed in the context of environmental impacts is the interaction between OWFs and maritime activities. This multi-dimensional interaction is often viewed as a marine spatial conflict, with both industries vying for adequate space in marine areas that may be already overcrowded with other multiple uses. 
Subsequently, this interaction between OWFs and maritime operations is the subject of a vast body of both academic and non-academic literature. For instance, Chircop and L'Esperance (2016) have discussed the legal aspects of this interaction, whilst there have also been some interesting investigations regarding vessel re-routing to reduce the costs associated with OWFs by authors such as Samoteskul et al. (2014).

The most widely explored topic under the broader thematic area of OWF-maritime interactions is the effect of OWFs on maritime navigational safety. There is consensus amongst stakeholders acknowledging that OWFs can pose risks to maritime operations in terms of reduced navigational safety (Wright et al. 2016; Mehdi and SchröderHinrichs 2016). Simply put, the presence of an OWF means more obstacles in the water that ships have to avoid. OWFs may also restrict the navigable space available to ships, leading to increased traffic density and an increased risk of collision. It is also well established that offshore wind turbines (OWTs) may interfere with ships' on-board navigation equipment such as radar and other radio-frequency devices (MARICO 2007; de la Vega et al. 2013; MCA 2016). All these factors, and more, can be detrimental to navigational safety.

\subsection{Environmental impact assessments (EIAs) and navigational risk assessments (NRAs)}

The complex, multi-dimensional impacts of OWFs need to be addressed before projects can be approved and licensed. This is usually done through a process called an 'environmental impact assessment'. The Secretariat of the Convention on Biological Diversity (SCBD) concisely defines EIA as 'a process of evaluating the likely environmental impacts of a proposed project or development, taking into account interrelated socio-economic, cultural and human-health impacts, both beneficial and adverse' (SCBD 2005). In essence, an EIA assesses the impacts of infrastructure like OWFs on other systems such as the marine environment, shipping, tourism and leisure craft activities, fishing and aquaculture, or even other existing offshore renewable energy installations (OREIs) in the area. A core feature of an EIA is to also assess the cumulative impacts, which are defined as the 'impacts on the environment which results from incremental impacts of the action when added to other past, present and reasonably foreseeable future actions'. (IEMA 2004). In other words, the cumulative impact assessment (CIA) stage in the EIA allows users to holistically understand the impact of a project like an OWF, by exploring the inter-relations between the different impacts, past, present and future.

Of all the different impacts related to OWFs, the focus of the current work is on the safety impact faced by ships. Shipping has an impact on where OWFs can be located, as well as an impact on the marine environment. Similarly, OWFs can have an impact on shipping efficiency (by forcing ships to take longer routes) and safety.

Maritime safety incidents can be very expensive for all parties involved, and in the absolute worst cases, such incidents can lead to human casualties or serious environmental damage. This is the core reason why authorities who are involved in the consenting and approval of OWFs tend to pay special attention to the maritime risks associated with OWFs (MCA 2013; BSH 2015; NIP 2017). In most coastal states, there are stringent processes requiring OWF owners/developers to demonstrate that they have thoroughly assessed the maritime risks and implemented adequate risk management measures (BSH 
2015; MCA 2013). These processes are generally referred to as navigational risk assessments (NRAs), and are often a part of the EIA studies for OWFs. Although NRAs are generally commissioned by OWF developers (only in the Netherlands that the state itself conducts the NRA) and checked by approval authorities as a part of the licensing process, there are also examples of NRAs being used as part of the marine spatial planning (MSP) process in countries like Belgium and the Netherlands.

The core premise of the NRA process is to assess the risk of maritime accidents ${ }^{1}$ in the vicinity of OWFs. In this case, 'risk' is defined as 'a combination of the probability and consequences of undesirable events that arise due to a permutation of passive hazards and active failures in a system or a process' (Mehdi and Schröder-Hinrichs 2018). The terms 'probability' and 'consequence' refer to the likelihood of an accident happening, and the nature and severity of an accident respectively. Thus, an NRA process essentially enables stakeholders to assess the probability, consequence and overall risk that an OWF poses to ship safety, through the use of various methods, models, tools and even stakeholder feedback. The probability of an accident in a NRA is generally assessed by considering vessel traffic movements in an area and by predicting the impact on vessel movements if an obstruction such as an OWF is installed, or if the safe room available for vessels is reduced due to an OWF. The probability is often calculated as a 'return period'-i.e. the expected length of time between accidents, given the number of ship movements in an area. The consequences of an accident are generally calculated by considering ship speed, types and sizes. Both the consequences and probabilities can be assessed either qualitatively or quantitatively in a NRA; the crucial element is to determine the change in the levels of probabilities and consequences (and therefore risk) before and after an OWF is built.

By conducting a NRA, it is therefore possible to evaluate whether or not the presence of an OWF will significantly increase navigational risk, beyond an unacceptable level. The 'acceptable' level of risk is itself defined as the maximum combined level of probability and consequence which would be acceptable to stakeholders of a system. Generally, the higher the probability of an accident, the lower the acceptable consequences - and vice versa. In other words, if the likelihood of an accident is high, the consequences must be low - and if the consequences are high, the probability must be low. The acceptable levels of risk are generally determined via stakeholder feedback at the initiation of a NRA process. If, during the NRA, the risk posed by an OWF to ship safety exceeds the acceptable level of probability and/or consequence, developers are required to implement risk-control options (RCOs). RCOs are measures which can reduce the probability and/or consequences of an accident. For instance, having collision-friendly turbines which cause minimal damage to ship hulls is a consequence-reducing RCO. Similarly, safety distances between OWFs and shipping lanes, or other routing measures, and nautical marks are probability-reducing RCOs, as they help to mitigate the likelihood of incidents. RCOs should be cost-effective, however-and if it is unfeasible to mitigate the risk, the project is scrapped.

NRAs often make use of existing methods and models. One common method recommended by several states for NRA is the International Maritime Organization's

\footnotetext{
${ }^{1}$ All countries considered in the present study require developers to assess the risk of all the following navigational accidents: powered and drifting contact (vessel-turbine) accidents, powered collision (vesselvessel) accidents and powered and drifting grounding accidents.
} 
(IMO's) Formal Safety Assessment (FSA), which is a five-step process, as follows (IMO 2002):

1. Hazard identification-What might go wrong?

2. Risk and hazard evaluation and assessment-How badly, and how likely? Step 2 is often combined with tools and models from probability and consequence estimation.

3. Identification of risk-control measures - Can the situation be improved, and how?

4. Cost-benefit analysis for risk-control measures-Is it worth implementing new measures?

5. Decisions, suggestions and recommendations-What should the next steps be?

As the offshore wind energy sector has evolved, so too have the OWF planning, consenting and approval processes (Gibson and Howsam 2010) - and NRAs are no exception. This evolution has also stimulated the development of various novel riskbased methods, models and tools that can be used specifically for NRAs around OWFs; authors such as Mehdi and Schröder-Hinrichs (2016) and Deeb et al. (2017) have conducted a comprehensive review of such tools and models. However, whether or not these developments are enough to address the challenges associated with increasingly complex and crowded marine areas remains to be seen.

\subsection{Problem description}

According to a recent report, Europe - the region leading the world in terms of the number of OWFs - has about 3.5k OWTs with a total installed capacity of $12.6 \mathrm{GW}$ as of 2016 (WindEurope 2017). The same report also mentions that an additional $4.8 \mathrm{GW}$ worth of offshore wind projects are currently under construction, $24.2 \mathrm{GW}$ have been consented, $7 \mathrm{GW}$ are pending approval and a staggering $65.6 \mathrm{GW}$ more projects are planned - in just European waters. If these projects become a reality, one can expect almost a sixfold increase in the number of OWTs and OWFs, in a region where marine areas are already quite crowded by shipping traffic and other marine uses such as fisheries, leisure activities, military activities and protected areas - not to mention test sites for other marine renewable energy developments, including wave and tidal generators.

Industry predictions also forecast that OWTs will get larger and more complex (e.g. larger rotors, floating turbines, ${ }^{2}$ vertical axis turbines), and OWFs will continue to grow in size and number over the upcoming years. There are also strong indications that OWFs continue to move further away from shore towards deeper water to better exploit the wind resource (WindEurope 2017; GWEC 2016).

Unquestionably, the burden on marine spatial planners, and approval and consenting authorities, is immense. In the context of the OWF-maritime interaction, these stakeholders have to ensure that OWFs have a minimal impact on the safety and efficiency of shipping operations - whilst simultaneously maximizing renewable energy generation potential and finding optimal locations for such installations. And in balancing the needs of the OWF and maritime industries, the leeway for over- or under-design for

\footnotetext{
${ }^{2}$ The world's first and largest floating OWF is due to be completed in 2017, off the coast of Scotland. It will consist of $5 \times 6 \mathrm{MW}$ Hywind turbines.
} 
safety and efficiency is minimal to none - particularly in already-crowded marine areas. Since planners and approval authorities rely on processes like NRAs to ensure that every bit of the available marine space is used as safely and efficiently as possible, these processes need to be quite robust. An NRA that is overly conservative may lead to inefficiency: ships may have to be unreasonably re-routed, or OWF layouts may have to be curbed unnecessarily due to overestimation of navigational risks. A poorly conducted NRA may also lead to reduced safety: an underestimation of the maritime risks could mean that adequate risk-control measures are not implemented, potentially exacerbating the probability and consequences of accidents even further. Therefore, a NRA - like everything in the age-old fable of Goldilocks, or the Swedish concept of 'lagom' — needs to be 'just right'.

There are thus two primary objectives of the present research:

1. To explore whether current NRA processes are robust enough to deal with an increasingly complex and crowded seascape and

2. To understand the shortcomings, if any, that need to be addressed in order to improve the coexistence of the maritime and offshore wind industries

\section{Literature review}

The first step in fulfilling the primary objectives is to conduct a thorough literature review. While there is ample literature that deals with NRA-related topics in general, not many publications address the shortcomings of existing NRA processes.

A bulk of the NRA-related literature stemming from academic and research sources deals with the development and theoretical application of various risk-based tools, methods and models that allow users to calculate the probability and consequences of maritime accidents in the vicinity of OWFs (Mehdi and Schröder-Hinrichs 2016; Deeb et al. 2017). By contrast, non-academic or 'grey literature'-which includes industrial standards, technical reports and approval studies conducted for planned and consented OWFs (NIP 2017) - provides plentiful examples of these tools, methods and models being applied in practice during actual NRAs. A cursory comparison of the academic and non-academic literature offers an interesting initial insight towards the shortcomings of existing NRA processes: it is apparent that academics and researchers have developed state-of-the-art tools, methods and models which seem to be underutilized by the industry.

One can also try to identify the shortcomings of existing NRA processes by attempting to understand what drives the development of certain models. It is fairly evident that a lot of recently developed models for NRA attempt to compensate for a 'lack of past knowledge': OWFs are still fairly novel developments, and the scarcity of accidents - whilst good - means that there is a certain lack of experience. In fact, a lot of the models and tools used for OWF NRA were originally developed for NRAs around oil platforms, bridges, quays and other marine structures - and adapted accordingly (Mehdi and Schröder-Hinrichs 2016). Although these tools have undoubtedly played an important role in helping to mitigate the risk of accidents near OWFs, there is always the lingering concern that the models used in current NRA processes may be under- or overly conservative, and thus do not allow sea-space to be efficiently utilized. 
This indicates another potential shortcoming of existing NRA processes: the lack of adequate input data (such as accident details and statistics) and experience.

In a recent study on seafarer perceptions of OWFs (Mehdi et al. 2017a), respondents were asked whether they were aware of any NRA studies for OWFs. Of the 150 respondents, only 24 (16\%) indicated that they were. And of these 24, only 13 indicated that they agreed with the results of NRAs. In fact, the findings of this study indicate a positive correlation between awareness of NRA studies and the level of concern regarding maritime safety risks associated with OWFs. NRAs should alleviate and not exacerbate the concerns of stakeholders such as seafarers. Thus, these findings point to yet another possible shortcoming of existing NRA processes: the inadequacy to address concerns of operational end users, including seafarers.

The sparse literature that is dedicated to comparing and identifying shortcomings in existing NRA processes provides some interesting information as well. In particular, a report by Ellis et al. (2008)—which compares various existing navigational risk models - identifies a lack of harmonization as another shortcoming that can be associated with OWF NRAs. The report also explicitly mentions a certain lack of transparency when it comes to models and tools that are used for NRA; specifically, the reports highlight some discrepancies in the probability calculations which are used to assess the likelihood of maritime accidents due to the presence of an OWF. The discussion and conclusion of this report suggest that despite the initiation of projects such as SAFESHIP ${ }^{3}$ or Safety at Sea-which attempted to address exactly these harmonization and transparency concerns - these shortcomings were not adequately addressed at the time.

Based on the findings of the literature review, the perceived shortcomings within NRA processes can be initially summarized as follows:

1. Lack of harmonization between the NRA processes in different countries

2. Lack of transparency within certain (commercial) models and tools

3. Lack of adequate input data, stemming from a lack of 'past experience' specific to OWFs

4. Inadequacy of NRA studies to alleviate the concerns of seafarers

5. Underutilization of novel models and methods that are developed by researchers

\section{Methodology}

A literature review alone is not enough to conclusively prove whether any of the aforementioned NRA-related shortcomings are actually of concern. The work of Ellis et al. (2008), for instance, is now nearly a decade old - which means that their findings may not necessarily be valid anymore. Similarly, issues that the current authors perceive to be shortcomings may not necessarily be viewed as such by stakeholders who are actually involved in the NRA process.

To overcome this gap in knowledge, representatives of OWF approval authorities from several different countries were surveyed. All respondents have a similar role in

\footnotetext{
${ }^{3}$ SAFESHIP (Reduction of Ship Collision Risks for Offshore Wind Farms)-EU Project conducted between 2003 and 2005, sponsored by European Commission through the 5th Research and Technological Development Framework Programme.
} 
their organization and are currently involved in the approval process for OWFs in their respective countries from their respective maritime departments. The organizations listed in Table 1 are those that have the most direct link to NRAs: in six of the seven countries, the respondents' organizations set out the guidelines for the NRA and also ensure that developers follow these guidelines when they conduct an NRA for an OWF license or approval; in the case of the Netherlands, the organization (Rijkswaterstaat) itself is responsible for conducting the NRA, disseminating the results amongst potential OWF developers and ensuring compliance with the findings at the approval stage. All the respondents, from each of the organizations, thus work hands-on with NRAs and have a technical nautical background which enables them to verify and validate the findings.

The survey was conducted as a structured interview. The respondents were sent a list of questions beforehand, so they could comment on it and prepare for the interview.

The interview questions were divided into two parts. The first set of questions was designed to collect information regarding the data, tools, methods and models that are commonly used for probability and consequence assessments during NRAs. The respondents were also asked to identify some key stakeholders that are involved in the NRA process. The purpose of these questions was to obtain an in-depth understanding of the NRA processes in different countries.

The second set of questions consisted of a list of ten statements. These statements were derived through the findings of the literature review $(\S 2)$, and were designed to determine whether any of the identified shortcomings within the existing NRA processes are (still) of concern. The respondents were asked to rate their agreement with each of these statements using a standard Likert scale of agreement (Vagias 2006); the levels on the five-point Likert scale ranged from 'strongly disagree' to 'strongly agree'. The respondents were also encouraged to identify any further shortcomings that they perceive within existing NRA processes.

Table 1 Respondents involved in current study

\begin{tabular}{|c|c|c|c|}
\hline Country & Organization & $\begin{array}{l}\text { No. of } \\
\text { respondents }\end{array}$ & Role \\
\hline United Kingdom & $\begin{array}{l}\text { Maritime \& Coastguard } \\
\text { Agency (MCA) }\end{array}$ & 1 & \multirow{7}{*}{$\begin{array}{l}\text { Verifying NRAs conducted by OWF } \\
\text { developers during licensing and } \\
\text { approval stages-specifically, } \\
\text { verifying compliance of OWFs } \\
\text { in terms of navigational safety } \\
\text { risks with reference to national } \\
\text { guidelines and regulations; } \\
\text { liaising with stakeholders during } \\
\text { approval and licensing process to } \\
\text { provide information pertinent to } \\
\text { NRA; participating in stakeholder } \\
\text { workshops }\end{array}$} \\
\hline Germany & $\begin{array}{l}\text { Budesamt für Seeschifffart } \\
\text { und Hydrographie (BSH) }\end{array}$ & 1 & \\
\hline Denmark & Søfartsstyrelsen (DMA)*† & 1 & \\
\hline The Netherlands & Rijkswaterstaat (RWS) $\ddagger$ & 1 & \\
\hline Belgium & FOD Mobiliteit (FOD)* & 1 & \\
\hline Sweden & Transportstyrelsen (STA) & 2 & \\
\hline United States of America & $\begin{array}{l}\text { United States Coastguard } \\
\text { (USCG) }\end{array}$ & 2 & \\
\hline
\end{tabular}

\footnotetext{
* Respondents are also involved in marine spatial planning processes in their country

$\dagger$ Respondent is also involved with aids to navigation

tResponsible for conducting the NRA and ensuring developers comply with findings
} 


\subsection{Sampling}

The respondents in the present study hail from seven different countries at different stages of offshore wind sector development. When deciding on which countries to choose, the primary factor that was considered is the cumulative offshore wind capacity (COWC) in each country. The COWC indicates the total installed offshore wind capacity, and can be used as a rough estimate to gauge the development status of the offshore wind industry in a country. Table 2 shows the countries covered in the present study, their COWC and their rank in terms of COWC on a global scale. The second-last column in Table 2 classifies the development status of the offshore wind industry in different countries based on COWC.

According to the Global Wind Energy Council (GWEC), there are a total of 15 countries which have OWFs or OWTs. The countries not included in the present study are China (1627 MW), Japan (60 MW), South Korea (35 MW), Finland (32 MW), Ireland $(25 \mathrm{MW})$, Spain $(5 \mathrm{MW})$, Norway $(2 \mathrm{MW})$ and Portugal $\left(0 \mathrm{MW}^{4}\right)$. Of the countries that are included, there are two 'established' (UK, DE), three 'evolving' (DK, $\mathrm{NL}, \mathrm{BE}$ ) and two 'emerging' (SE, US) in terms of COWC. The present sample therefore adequately represents countries at the three different stages of offshore wind industry development.

\section{Results and discussion}

\subsection{A comparison of existing NRA processes}

As the challenges associated with maritime operations in the vicinity of OWFs are more or less comparable in different areas, one can expect to find quite of lot of similarities in the NRA processes of various countries. At the same time, the different stages of offshore wind industry development in various countries are a reason to believe that there may also be differences in these NRA processes. A literature review - such as the one conducted by Ellis et al. (2008) or Mehdi and Schröder-Hinrichs (2016) - points towards both similarities and dissimilarities amongst the NRA frameworks, models, methods and tools used by different countries, but is inconclusive in proving whether there are more differences than similarities in the actual NRA processes.

To further understand the difference and similarities, it is therefore important to learn directly from the stakeholders who are integrally involved in these NRA processes. Such stakeholders are generally the ones who are involved in the planning and/or approval of OWFs from the maritime side. Subsequently, this sub-section summarizes the key elements of various NRA processes - as described in various national guidance documents and as explained by people involved in the maritime-related planning and approval of OWFs in different countries. Tables 3 and 4 summarize the findings in a comparative manner.

\footnotetext{
${ }^{4}$ The only OWT in Portugal—a 2-MW floating turbine named WindFloat 1-was decommissioned in 2016.
} 
Table 2 COWC in different countries, global rank by COWC and classification based on COWC. COWC data is from GWEC ( 2016)

\begin{tabular}{llllll}
\hline Country & Abbreviation & $\begin{array}{l}\text { COWC } \\
(\mathrm{MW})\end{array}$ & Global rank & Classification & Notes \\
\hline United Kingdom & $\mathrm{UK}$ & 5156 & 1 st & Established & [COWC $>2500 \mathrm{MW}]$ \\
Germany & DE & 4108 & 2 nd & Established & \\
Denmark & DK & 1271 & 4 th & Evolving & {$[2500 \mathrm{MW}>$ COWC } \\
The Netherlands & $\mathrm{NL}$ & 1118 & 5 th & Evolving & $>500 \mathrm{MW}]$ \\
Belgium & $\mathrm{BE}$ & 712 & 6 th & Evolving & \\
Sweden & $\mathrm{SE}$ & 202 & 7 th & Emerging & {$[\mathrm{COWC}<500 \mathrm{MW}]$} \\
United States of America & $\mathrm{US}$ & 30 & 11 th & Emerging & \\
\hline
\end{tabular}

\subsubsection{United Kingdom}

When it comes to energy generation from offshore wind, the undisputed leader is the UK. With 1472 OWTs currently installed, the UK has the greatest COWC (5156 MW) of all the countries with OWFs as shown in Table 2. The UK also boasts the largest OWF in the world-London Array, a 630-MW OWF with 175 installed turbines. As mentioned earlier, the world's first and largest floating OWF-commissioned in 2017-is also in the UK, just off the coast of Scotland.

A marine license is necessary for all OWFs in the UK, and it is granted by the various devolved authorities - such as the Marine Management Organization (MMO) in England or Marine Scotland in Scotland. In order to obtain a marine license, OWF developers need to conduct a NRA. The purpose of the NRA in the UK, like elsewhere, is quite simple: to evaluate the risk to shipping without ('base-case') and with ('futurecase') the proposed OWF - and to demonstrate that the proposed OWF will not lead to unacceptably high navigational risks. The devolved authorities consult the Maritime and Coastguard Agency (MCA), as well as other relevant stakeholders, to ensure that a NRA conducted by an OWF developer is valid and adequate.

The UK's significant NRA experience is well reflected in comprehensive guidance documents, which are developed for OWF developers by authorities such as the MCA. These documents include the well-known 'Methodology for assessing the marine navigational safety and emergency response risks of offshore renewable energy installations' (MCA 2013) and 'MGN 543 (M+F) Safety of Navigation: Offshore Renewable Energy Installations - UK Navigational Practice, Safety and Emergency Response' (MCA 2016). Both these documents provide a comprehensive list of factors (e.g. vessel traffic, types of vessels, traffic characteristics, location of routes, routing measures, bathymetry, waves, winds, currents, OWF layout, OWT marking and lightings, effect of turbines on navigational equipment, etc.) - as well as a non-exhaustive list of stakeholders (e.g. RNLI, lighthouse authorities, Chamber of Shipping, recreational shipping, local fishermen, shipowners and operators, etc.) that need to be considered during a NRA. These factors and stakeholders were also mentioned by the respondent during their interview. 
Table 3 Comparison of NRA process in the seven countries

\begin{tabular}{|c|c|c|c|c|c|c|c|c|}
\hline & & UK & DE & DK & NL & BE & SE & US \\
\hline 1. & $\begin{array}{l}\text { Is a marine licence necessary for } \\
\text { offshore wind farm (OWF) } \\
\text { approval in your country? }\end{array}$ & \multicolumn{7}{|c|}{ Yes } \\
\hline 2. & $\begin{array}{l}\text { Is a navigational risk assessment } \\
\text { (NRA) necessary for OWF } \\
\text { approval in your country? }\end{array}$ & \multicolumn{6}{|c|}{ Yes } & $\begin{array}{l}\text { No, but } \\
\text { generally } \\
\text { included }\end{array}$ \\
\hline 3. & $\begin{array}{l}\text { Who is responsible for conducting } \\
\text { this NRA? }\end{array}$ & \multicolumn{3}{|c|}{ OWF Developer } & $\begin{array}{l}\text { Federal } \\
\text { maritime } \\
\text { authority }\end{array}$ & \multicolumn{3}{|c|}{ OWF Developer } \\
\hline 4. & $\begin{array}{l}\text { Do you have any national } \\
\text { guidelines on NRA? }\end{array}$ & \multicolumn{2}{|c|}{ Yes } & Internal only & \multicolumn{4}{|c|}{ Yes } \\
\hline 5 . & $\begin{array}{l}\text { Do you require the use of any } \\
\text { specific models, tools or methods } \\
\text { when a NRA is conducted? }\end{array}$ & $\begin{array}{l}\text { No. } \\
\text { Recommend } \\
\text { FSA; } \\
\text { ANATEC's } \\
\text { COLLRISK } \\
\text { model } \\
\text { commonly } \\
\text { used by most } \\
\text { often by } \\
\text { developers to } \\
\text { compare base } \\
\text { case vs. } \\
\text { future case } \\
\text { risk. }\end{array}$ & $\begin{array}{l}\text { Yes. German } \\
\text { Hazardous } \\
\text { Incident } \\
\text { Ordinance } \\
\text { (Störfallveror } \\
\text { dnung), the } \\
\text { British Safety } \\
\text { Case } \\
\text { Regulations } \\
\text { for offshore } \\
\text { installations, } \\
\text { IMO } \\
\text { regulations } \\
\text { for risk } \\
\text { assessment to } \\
\text { be followed. } \\
\text { Models from } \\
\text { GL (DNV- } \\
\text { GL) most } \\
\text { commonly } \\
\text { used by } \\
\text { developers to } \\
\text { compare base } \\
\text { case vs. } \\
\text { future case } \\
\text { risk. }\end{array}$ & $\begin{array}{l}\text { No. } \\
\text { Recommend } \\
\text { FSA; } \\
\text { DNV } \\
\text { MARCS } \\
\text { model, and } \\
\text { models from } \\
\text { COWI and } \\
\text { Rambøll } \\
\text { most } \\
\text { commonly } \\
\text { used by } \\
\text { developers to } \\
\text { compare base } \\
\text { case vs. } \\
\text { future case } \\
\text { risk. }\end{array}$ & $\begin{array}{l}\text { No. } \\
\text { Recommend } \\
\text { FSA; } \\
\text { MARIN's } \\
\text { SAMSON } \\
\text { model used } \\
\text { most } \\
\text { commonly to } \\
\text { compare base } \\
\text { case vs. } \\
\text { future case } \\
\text { risk. }\end{array}$ & $\begin{array}{l}\text { No. } \\
\text { Recommend } \\
\text { FSA; } \\
\text { MARIN's } \\
\text { SAMSON } \\
\text { model used } \\
\text { most } \\
\text { commonly to } \\
\text { compare base } \\
\text { case vs. } \\
\text { future case } \\
\text { risk }\end{array}$ & $\begin{array}{l}\text { No. } \\
\text { Recommend } \\
\text { IALA's } \\
\text { iWRAP- } \\
\text { MKII model; } \\
\text { SSPA model } \\
\text { most } \\
\text { commonly } \\
\text { used by } \\
\text { developers to } \\
\text { compare base } \\
\text { case vs. } \\
\text { future case } \\
\text { risk. }\end{array}$ & $\begin{array}{l}\text { No. } \\
\text { Recommend } \\
\text { 'What-if' } \\
\text { analysis } \\
\text { amongst } \\
\text { other tools. }\end{array}$ \\
\hline 6. & $\begin{array}{l}\text { Is there a minimum standard of } \\
\text { consequence assessment? For } \\
\text { instance, do you require the } \\
\text { consequences of accidents to be } \\
\text { modelled qualitatively, } \\
\text { quantitatively, analytically, } \\
\text { empirically, numerically? }\end{array}$ & $\begin{array}{l}\text { No. Just } \\
\text { require } \\
\text { comparison } \\
\text { of base case } \\
\text { vs. future } \\
\text { case risk. }\end{array}$ & $\begin{array}{l}\text { Yes. } \\
\text { developers } \\
\text { do need to } \\
\text { show that } \\
\text { turbines are } \\
\text { collision- } \\
\text { friendly for a } \\
\text { specific } \\
\text { vessel } \\
\text { drifting at } 2 \\
\mathrm{~m} / \mathrm{s} \text {, using } \\
\mathrm{FEA}\end{array}$ & \multicolumn{5}{|c|}{$\begin{array}{l}\text { No. Just require comparison of base case vs. future case risk. } \\
\text { *In DK, developers do need to show that turbines are collision-friendly, though this } \\
\text { can be qualitatively }\end{array}$} \\
\hline 7. & $\begin{array}{l}\text { Is there a minimum standard of } \\
\text { probability assessment? For } \\
\text { instance, do you require the } \\
\text { consequences of accidents to be } \\
\text { modelled analytically, empirically, } \\
\text { numerically? }\end{array}$ & $\begin{array}{l}\text { No. Just } \\
\text { require } \\
\text { comparison } \\
\text { of base case } \\
\text { vs. future } \\
\text { case risk. }\end{array}$ & $\begin{array}{l}\text { Yes. } \\
\text { Numerical } \\
\text { calculation } \\
\text { required. }\end{array}$ & \multicolumn{5}{|c|}{ No. Just require comparison of base case vs. future case risk. } \\
\hline 8. & $\begin{array}{l}\text { Are there any specific factors that } \\
\text { must be considered in a NRA - } \\
\text { e.g. - specific ship type, size, } \\
\text { speed, weather conditions, etc.? }\end{array}$ & \multicolumn{7}{|c|}{$\begin{array}{l}\text { Ship traffic, speeds and types through AIS data, dynamic (wind, wave, tides, currents, etc.) and static (bathymetry, } \\
\text { hydrographic features, layout of channels, etc.) environmental conditions, OWF location and layout }\end{array}$} \\
\hline 9. & $\begin{array}{l}\text { Are there any guidelines for } \\
\text { approving a wind farm with } \\
\text { regards to navigation safety? }\end{array}$ & $\begin{array}{l}\text { No. Case-by- } \\
\text { case basis. }\end{array}$ & $\begin{array}{l}\text { Yes. } \\
\text { Minimum } \\
100 \text { year } \\
\text { return period; } \\
\text { turbine must } \\
\text { be collision } \\
\text { friendly, and } \\
\text { not rupture } \\
\text { hull of a pre- } \\
\text { determined } \\
\text { vessel } \\
\text { drifting in to } \\
\text { it at } 2 \mathrm{~m} / \mathrm{s}\end{array}$ & \multicolumn{5}{|c|}{$\begin{array}{l}\text { No. Case-by-case basis. } \\
\text { *In DK, turbine must be collision friendly. }\end{array}$} \\
\hline
\end{tabular}

Similar answers for each question are coloured green and discrepant answers are orange

The maritime operations that are considered during a NRA in the UK include passing shipping traffic, wind farm support vessel (WSV) operations, OWF installation operations and emergency operations such as search and rescue (SAR). Decommissioning operations are not explicitly covered, nor are operations in ports and harbours, the latter of which are dealt separately with by harbour 
Table 4 Comparison of the scope of the NRA process in the s countries

\begin{tabular}{|c|c|c|c|c|c|c|c|c|c|}
\hline & & & UK & DE & DK & $\mathbf{N L}$ & BE & SE & US \\
\hline \multirow[t]{7}{*}{10.} & $\begin{array}{l}\text { Which o } \\
\text { operatio } \\
\text { NRA in }\end{array}$ & $\begin{array}{l}\text { e following maritime } \\
\text { are considered during a } \\
\text { ur country? }\end{array}$ & & & & & & & \\
\hline & a. & Passing vessels & Yes & Yes & Yes & Yes & Yes & Yes & Yes \\
\hline & b. & $\begin{array}{l}\text { Support vessel } \\
\text { operations }\end{array}$ & Yes & No & Yes & Yes & Yes & Yes & Yes \\
\hline & & $\begin{array}{l}\text { OWF Installation } \\
\text { Operations }\end{array}$ & Yes & No & Yes & Yes & Yes & Yes & Yes \\
\hline & d. & $\begin{array}{l}\text { OWF } \\
\text { Decommissioning } \\
\text { Operation }\end{array}$ & No & No & Yes & Yes & Yes & Yes & Yes \\
\hline & e. & $\begin{array}{l}\text { Emergency } \\
\text { Operations including } \\
\text { Search \& Rescue } \\
\text { (SAR) }\end{array}$ & Yes & No & Yes & Yes & Yes & Yes & Yes \\
\hline & f. & $\begin{array}{l}\text { Operations in ports \& } \\
\text { harbours that deal } \\
\text { with OWF activities }\end{array}$ & No & No & Yes & Yes & No & Yes & Yes \\
\hline \multicolumn{10}{|c|}{$\begin{array}{l}\text { 11. Which phases of a OWF's } \\
\text { lifecycle are covered by the NRA } \\
\text { in your country? }\end{array}$} \\
\hline & & $\begin{array}{l}\text { Installation \& Cable } \\
\text { Laying }\end{array}$ & Yes & Yes & Yes & Yes & Yes & Yes & Yes \\
\hline & b. & Operation & Yes & Yes & Yes & Yes & Yes & Yes & Yes \\
\hline & c. & Decommissioning & No & Yes & Yes & Yes & No & Yes & No \\
\hline
\end{tabular}

Phases and processes covered by NRA are in green; those not covered by NRA in a country are in orange

authorities. The NRA also does not cover the decommissioning phase of an OWF's life cycle.

The guidance documents from the UK recommend that developers follow the five-step Formal Safety Assessment (FSA) methodology (IMO 2002). FSA — which has also been adapted by the International Maritime Organization (IMO)_allows decision makers (in this case, the licensing and approval authorities MMO and MCA) to evaluate the risks, costs and benefits of a proposed activity or system and to propose adequate risk-control options, making it ideally suited for a process such as NRA.

Within the FSA methodology, users are free to choose which models and tools they want to use for probability and consequence calculations. In the UK, there are no minimum requirements as to whether these models or tools should be qualitative, quantitative, numerical, empirical, probabilistic, deterministic, etc. Thus, even though the two guidance documents cited above (MCA 2013, 2016) mention possible use of numerical models and simulations, OWF developers are not obliged to use and adhere to these specifically - and are free to use any models or tools for probability or consequence calculations that they deem fit.

A cursory look on the National Infrastructure Planning Portal (NIP 2017), which contains environmental impact assessment (EIA) and NRA studies for various UKbased OWFs, indicates that nearly all developers ${ }^{5}$ use the COLLRISK model from Anatec UK Ltd. (Anatec 2017). This quantitative, probabilistic model primarily relies on vessel traffic data to estimate the difference in risk of navigational accidents in an

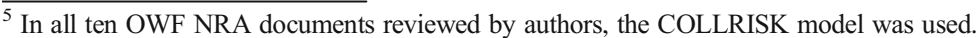


area before and after an OWF is constructed. The COLLRISK model also uses estimates of impact energy (using kinetic energy formulae), as well as past accident statistics, to predict the probability and level of consequences, such as loss of life, injuries or environmental damage.

Nevertheless, the adequacy of a NRA in the UK is determined on a strictly case-bycase basis. Therefore, developers should be able to demonstrate that they have considered all listed factors thoroughly, whilst giving reasonable justification for the methods, models and tools that they have used.

Similarly, each OWF in the UK is also approved on a case-by-case basis, which means that there are no specific limits on how low the probability and/or consequences of OWF-related navigational accidents should be. In other words, the 'acceptable' risk limits for each OWF can be different - and whether an OWF gets the go ahead is decided on the outcome of the NRA, which includes the results of hazard identification (HAZID) workshops (wherein the risks are identified), a formal risk assessment and comparison of base and future case risks, and the discussions of stakeholder consultations (wherein risk identification, analysis and control options are discussed).

\subsubsection{Germany}

Germany has the second-largest COWC after the UK, with 947 installed OWTs as of 2016. There has been a flurry of OWF-related activities in Germany over the last two years in particular: of the $4108 \mathrm{MW}$ total COWC, $2282 \mathrm{MW}$ worth of turbines were installed in 2015 alone - with a further 813 MW installed in 2016.

In Germany, the licensing of all OWFs in the exclusive economic zone (EEZ) is done by the Federal Maritime and Hydrographic Agency of Germany (Bundesamt für Seeschifffahrt und Hydrographie, or BSH). The NRA is a part of the licensing process, and is checked by the Directorate-General for Waterways and Navigation ${ }^{6}$ (Generaldirektion Wasserstraßen und Schifffahrt, or GDWS).

Some of the early (and already quite comprehensive) documents for OWF NRA were developed by the class-society Germanischer Lloyd more than 15 years ago (GL 2002) and updated nearly a decade ago (GL 2008). Subsequently, some of the early NRA studies used models developed by GL such as COLWT (GL 2002, 2008; Ellis et al. 2008). In more recent years, updated NRA guidance documents have been produced by federal authorities in Germany. The BSH, for instance, has developed a construction standard for OWFs - 'Minimum requirements concerning the constructive design of offshore structures within the Exclusive Economic Zone' (BSH 2015) which provides an overview of the risk assessment process, as well as details about accident-consequence estimation. This document is used in combination with 'AGRichtwerte' — a document developed by GDWS — which provides guidelines for probability assessment (in German). Other relevant documents ${ }^{7}$ containing guidance on NRA include an implementing directive on marine impacts of OWFs (BMVI 2014a); a

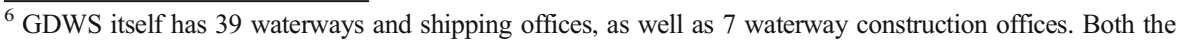
BSH and GDWS are a part of the Waterways \& Shipping Administrations of the Federal Government (Wasserstraßen- und Schifffahrtsverwaltung des Bundes, or WSV). The WSV is one of 9 directorates of the Federal Ministry of Transport \& Digital Infrastructure (Bundesministeriums für Verkehr und digitale Infrastruktur, or BMVI).

${ }^{7}$ The other aforementioned documents are available in German only.
} 
safety framework for OWFs (BMVI 2014b); a framework to ensure the proper implementation of traffic regulations in the vicinity of OWFs, including guidance on marking of offshore turbines (GDWS 2014a); and a directive to ensure the safety and security of ship traffic in the vicinity of OWFs (GDWS 2014b). These documents list the factors that need to be considered during NRAs (e.g. vessel traffic; OWF location and layout; environmental conditions including wind, weather, ice, fog, bathymetry, effect on navigational equipment, etc.) - and also identify important stakeholders that should be consulted during the process (e.g. GDWS, German Sailing Association, fisheries associations, etc.). The factors and the stakeholders which are considered during a NRA are similar in both the UK and Germany, and were confirmed by the German respondents in their survey responses during the present study.

The focus of NRAs in Germany is primarily on assessing and managing the impact of OWFs on passing shipping traffic. WSV operations, installation and decommissioning operations, emergency response operations and operations in ports and harbours are not explicitly dealt with during the NRA process. A NRA in Germany covers all phases of an OWF's life cycle, including installation and cable laying, operation and decommissioning.

The guidance documents by BSH clearly state that 'the method of risk classification and analysis shall be based on the German Hazardous Incident Ordinance (Störfallverordnung), the British Safety Case Regulations for offshore installations and the IMO regulations' (BSH 2015).

In Germany, the probability of navigational accidents must be calculated numerically whilst accounting for factors such as ship type, size, speed, weather conditions, location and layout of OWF, etc.; the GDWS provides inputs on which ship types and sizes need to be considered. Once the probability of a navigational accident is calculated, it can be categorized within a qualitative band (frequent, occasionally, rare, extremely rare) as per the guidance of BSH ( 2015). The emphasis in Germany is more on vessel-turbine collisions than on vessel-vessel collisions or vessel groundings which may also be caused by an OWF restricting navigable space. A BMVI working group has deemed that there should not be more than one OWF-related navigational accident every 100 years; any frequency higher than this is considered unacceptable. This is a very different approach than that of the UK, where the so-called return period of vesselturbine accidents (i.e. the minimum number of years between accidents) is determined on a case-by-case basis rather than a fixed, generic value. It is also interesting to note the requirement for a numerical probability calculation-which is again in stark contrast with the UK where there are no minimum model- or tool-related obligations on developers.

Furthermore, the focus on consequence assessment is also more detailed and explicit in Germany than in the UK and most other countries. Developers are required to use finite-element (FE) simulation programmes to model an accident between a turbine and a reference vessel(s). Developers are, however, free to choose their preferred software package and modelling tools for the FE calculations. Examples of FE analyses of shipturbine collisions can be found in the works of Biehl and Lehmann (2006), Le Sourne et al. (2015) and Bela et al. (2017) amongst many others as listed by Mehdi and Schröder-Hinrichs (2016) and Deeb et al. (2017).

The purpose of the FE calculations is to understand the behaviour of turbine collapse and to ensure that the support structure of an OWT is 'collision friendly'-i.e. 'if an 
offshore wind turbine, as a consequence of collision, does not fall onto the ship, the ship remains floatable and there is no leakage of pollutants' (BSH 2015). In other words, a turbine must not rupture the hull of a ship under specified conditions; the conditions are specified by the BMVI and assume that a reference ship, of a given type and structural configuration, drifts into the turbine at a speed of $2 \mathrm{~m} / \mathrm{s}$. The BSH ( 2015) guidance lists further specific criteria that must be met during the FE calculation stages, including a list of acceptable assumptions for the model.

Ideally, several different scenarios should be modelled using FE calculations. Following the FE calculations, qualitative consequence levels (catastrophic, serious, significant, insignificant) are assigned to each scenario based on the expected condition of the OWT, the expected damage to the ship, the expected environmental damage and/ or the expected casualties and fatalities. Developers are then required to use a risk matrix to 'combine' the consequence and probability levels into a given risk value for each scenario. The combined risk value for each scenario must be below a certain threshold to be acceptable, as specified by BSH ( 2015).

Traditionally speaking, there has been widespread use of Germanischer Llloyd's (now DNV-GL) collision models in Germany, who also provided input for NRA guidelines in the country. The package LS-DYNA has also been widely used to conduct FE modelling of vessel-turbine collisions. As mentioned above, however, developers are free to choose the models for both probability and consequence assessments.

Compared to other countries, Germany has opted for a more rigid approach to NRA. The lack of flexibility, however, does offer certain apparent advantages in terms of standardization, transparency and harmonization. Whether this approach is more or less effective than that of other countries remains to be seen.

\subsubsection{Denmark}

Denmark is truly a pioneering country when it comes to offshore wind energy. The first-ever OWF, Vindeby, was commissioned near Lolland in Denmark, in 1991. And after producing 243 GWh of energy over 25 years, Vindeby is finally being decommissioned. The legacy of offshore wind, however, remains strong in Denmark, where there are currently 517 installed OWTs, with a COWC of $1271 \mathrm{MW}$. This year, the Danish Energy Agency (DEA) produced a report detailing the Danish experiences of OWFs (DEA 2017).

The licensing of OWFs is handled by the DEA. Developers are required to conduct an EIA for each OWF, and a crucial part of this EIA is the NRA. The NRA is checked and validated by the Danish Maritime Authority (DMA).

While the DMA has internal guidelines on NRA, there are no specific public documents providing guidance on the topic. Nevertheless, the in-depth interview with the Danish authorities provided a thorough insight into the NRA process. The factors and stakeholders that are considered in Denmark are very similar to those that are considered in the UK or Germany. The factors that are considered during a NRA include vessel traffic data, ship routes, OWF-related data, effect of turbines on navigational equipment, and static and dynamic environmental conditions, as well as the presence of existing risk-control options such as vessel traffic service (VTS) or traffic separation schemes (TSS). The Danish authorities explicitly listed pilots, VTS 
operators, local port authorities, fishermen, leisure boat owners and operators as well as leisure ports as important stakeholders. The list of both factors and stakeholders is nonexhaustive, as stated by the interview respondents.

In Denmark, the NRA covers all maritime operations, including passing vessels, WSV operations, OWF installation and decommissioning operations, emergency response operations and even operations in ports and harbours that deal with OWF activities. The NRA also covers all phases of an OWF's life cycle, including installation and cable laying, operation and decommissioning.

The DMA - like the British MCA — strongly recommends the use of FSA as the overarching method for NRA. Developers can opt for a different method with reasonable justification, but generally comply with DMA's recommendation. As in the UK, developers are free to choose which models and tools they use for probability and consequence assessment stages within the FSA. There are no minimum requirements as to whether probability and/or consequence assessments need to be qualitative, quantitative, numerical, probabilistic, etc.

Generally, however, the starting point of a NRA in Denmark is the consideration of current and predicted AIS data to quantitatively estimate the probability of navigational accidents for different vessel types in the vicinity of OWFs. This estimation should account for the various factors listed above, such as vessel traffic, OWF location and layout, configuration of shipping routes and environmental conditions. If the return period is found to be too low, then developers need to demonstrate that they will implement adequate risk-control measures - particularly to mitigate the consequences of navigational accidents. This discussion is usually a part of HAZID workshops.

There are no strict demands in terms of consequence assessment either-and certainly no requirements for FE calculations like in Germany. That being said, the turbines do need to be collision friendly, but this is something that is generally addressed qualitatively during discussions in HAZID workshops.

In previous years, OWF developers in Denmark have often made use of Det Norske Veritas' (DNV's) 'Marine Accident Risk Calculation System' (MARCS) model (Ellis et al. 2008). This model combines AIS data with OWF location and layout to assess the frequency of accidents before and after an OWF is installed. The model also has the capability to estimate the probability and level of consequences, and can provide a rough assessment of environmental damage through probabilistic damage calculations. This detail of consequence assessment may not be needed for qualitative discussions, but it is nevertheless a good option to have. In more recent years, companies such as COWI and Rambøll have also conducted NRAs for OWFs in Denmark.

Each OWF in Denmark is approved on a case-by-case basis - and thus, there are no generic requirements about how low the probability or consequences need to be. If the accident return period is too low, then the approval of an OWF may hinge on adequate risk-control options being implemented; these measures may seek to reduce to probability or, more often, the consequences of navigational accidents associated with OWFs. Measures include re-routing of shipping lanes to increase safe space for ships, marking and nautical aids, proper marking on charts and collision-friendly wind turbine design in case of accidents.

Overall, the approach of Denmark towards NRA follows more closely the approach of the UK rather than that of Germany. That being said, the requirements for turbines to be collision friendly is an idea championed by Germany more so than the UK. 


\subsubsection{The Netherlands}

The Netherlands is another pioneering country when it comes to wind energy. The very mention of the nation evokes images of quaint, centuries-old windmills in fields of tulips. It is therefore apt to see that the Netherlands has a strong OWF sector as well. As of 2016, there are 365 OWTs with a COWC of $1118 \mathrm{MW}$ in the Netherlands. ${ }^{8}$

The licensing of OWFs in the Netherlands falls under the 'Kavelbesluiten' (part of the Act on offshore wind energy), and also relates to the Water Act. The Water Act also provides the general rules for all OWFs within the EEZ. The authority responsible for the licensing of OWFs is the Ministry of Economic Affairs and Climate Policy (MEACP), which makes decisions in liaison with other federal authorities such as the Ministry of Infrastructure and Water Management (MIW) ${ }^{9}$; the Netherlands Enterprise Agency (RVO.nl) executes the SDE+ (in Dutch: Stimulering Duurzame Energieproductie) operating grant, offshore wind energy subsidy and permit tenders on behalf of MEACP.

The Dutch government itself is responsible for producing an EIA, called a marine environmental effects report (MER), as well as the NRA. The MER and NRA are then passed on to the developers, along with specific design requirements for potential OWFs. Rijkswaterstaat, the part of the Ministry of Infrastructure and Water Management (MIW) that is responsible for the design, construction, management and maintenance of the main infrastructure facilities, is responsible for conducting the NRA and verifying that developers comply with the NRA findings. The approach of the Dutch authorities towards the NRA thus differs from that of the other coastal states covered in this study. While the other coastal states require the OWF developers to conduct NRAs and EIAs, these processes are led and conducted by the governmental authorities in the Netherlands. This means that in other coastal states, the NRA is generally a part of the approval and licensing stages only-whereas in the Netherlands, the NRA is the same across the planning, approval and licensing stages. This has the added advantage of ensuring that there are minimal differences between OWFs-as-planned and OWFs-as-approved.

There are publicly available guidelines pertaining to safe navigation around OWFs. Most of the documents, ${ }^{10}$ however, are in Dutch. This includes the important 'Bijlage 4: Reglementen, voorschriften en verkeersregels voor scheepvaart die' - an appendix which deals with rules and regulations of shipping traffic, with a particular focus on safe-passing distances to OWFs. An equivalent and comprehensive document is also available in English (MIE and MEA 2014). The latter document lists the factors and

\footnotetext{
${ }^{8}$ These numbers, cited by WindEurope, differ to the official Dutch figures of 289 offshore turbines and 957 MW COWC. The discrepancy is because WindEurope includes the turbines at Lake Ijsselmeer, whereas the Dutch authorities do not. For the purposes of this report, the Dutch figures are more accurate as 'offshore' turbines are those beyond the defined marine baseline of a country, where the baseline is defined as per UNCLOS. For reasons of consistency however, the figures from WindEurope are cited in the text.

${ }^{9}$ Following the Dutch general elections in March 2017, the Ministry of Infrastructure and the Environment (MIE) is now called the Ministry of Infrastructure and Water Management (MIW). The spatial department of the old Ministry of Infrastructure and the Environment is now part of the Ministry of the Interior and Kingdom Relations.

The old Ministry of Economic Affairs is now called the Ministry of Economic Affairs and Climate Policy. Note that the former Ministry of Economic Affairs was also responsible for MPA policy and fisheries. These task are now in our new Ministry of Agriculture, Nature and Food quality.

${ }^{10}$ Available from www.noordzeeloket.nl
} 
stakeholders that are taken into consideration when discussing safety of navigation. Factors which are taken into account include vessel traffic characteristics, ship speed, sizes and manoeuvrability, static and dynamic environmental conditions, and OWF layout and location. Important stakeholders for NRA - as listed by the interview respondent-include, but are not limited to, the OWF sector, commercial and recreational shipping, fishermen, harbour authorities and various governmental departments. It is apparent that the factors and stakeholders considered during a NRA in the Netherlands are similar to those considered during NRAs in other countries such as the UK, Germany and Denmark.

In the Netherlands, a NRA should cover all maritime operations, including passing vessels, WSV operations, OWF installation and decommissioning operations, emergency operations, as well as operations in ports and harbours that deal with OWF activities. The NRA also covers all phases of an OWF's life cycle from installation, through operation, to decommissioning.

A NRA in the Netherlands can be conducted for two purposes related to OWFs. The first purpose is proposal of risk-control measures (e.g. new routing measures) around existing OWFs. For this purpose, the NRA is conducted by the Dutch authorities and submitted to the IMO. The IMO-recommended FSA methodology (IMO 2012) is followed for such submissions - and authorities prefer to use the quantitative 'Safety Assessment Models for Shipping and Offshore in the North Sea' (SAMSON) model (van der Tak 2010; Ellis et al. 2008), developed by the Marine Research Institute of the Netherlands (MARIN), for the probability and consequence calculation stages in the FSA. When proposing routing measures, the Dutch authorities follow the guidelines of the World Association for Waterborne Transport Infrastructure (PIANC) with regard to minimum waterway width, and also rely on the results from the research institute MARIN which have determined how much space is needed between waterways and OWF boundaries. Using an NRA to re-route shipping lanes around existing OWFs is an unprecedented action that was taken by the Netherlands, as normally, in other coastal states, shipping lanes are re-routed before OWFs have been built, in anticipation, often during planning and/or scoping stages. Nevertheless, it is a positive step to ensure navigational safety, and set a good example for other coastal states to follow, in case they ever recognize the need to retroactively adopt their risk-control measures, due to changes in shipping traffic and/or environmental conditions for instance.

The second purpose of an NRA is the approval of OWFs (which is common across the other coastal states). In this case, a NRA is used to compare base-case with future-case scenarios, and is conducted by MIW and Rijkswaterstaat. As mentioned earlier, the results of the NRA (as well the overarching MER) are presented to developers, along with specific design specifications for potential wind farms. The federal authorities (i.e. MIW and Rijkswaterstaat) are then responsible for ensuring that developers adhere to the guidelines during the approval and licensing phase. The Dutch authorities prefer to follow the FSA methodology, and favor the use of MARIN's quantitative SAMSON model for probability and consequence calculations ${ }^{11}$ for OWF-approval NRAs as well.

\footnotetext{
${ }^{11}$ Whilst Denmark and the UK also advocate the use of the FSA methodology for NRA, they do not have any particular recommendations as to which models should be used for probability and consequences calculations within the FSA.
} 
SAMSON, like most other commercial models, relies on AIS data to calculate the risk of navigational accidents in the vicinity of OWFs. It can be used to calculate and compare the probability and consequences of navigational accidents for various basecase (i.e. no OWF) and future-case (i.e. OWFs in different layouts/locations) scenarios. When calculating the probability of drifting or powered accidents near OWFs, SAMSON can account for various specific factors such as ship types, sizes and speeds, effect of OWTs on ships' navigational equipment, as well as static and dynamic environmental factors - not to mention risk-control options such as VTS, TSS, availability of tugs in an area, etc. SAMSON also performs quantitative consequence assessment, and can be used to predict the damage to turbines and ships, environmental damage in terms of oil spills or human casualties through the use of complex semi-analytical/empirical formulae. Furthermore, SAMSON is also able to assess the economic- and efficiency-cost of various risk-control options (e.g. rerouting), which makes it a good tool for cost-benefit analyses - and an ideal complement to the FSA methodology. Despite all the positives, however, SAMSON is a commercial tool, which means that certain elements within it may not be entirely transparent to the general public.

It is important to reiterate that the use of SAMSON is highly recommended, but not obligatory. Whilst most OWF developers - and the Dutch authorities themselves - use SAMSON, it is possible to employ other models and tools for OWF NRA, with reasonable justification.

Like in Denmark, or the UK, OWFs in the Netherlands are approved on a case-bycase basis. Each individual NRA is generally discussed with operational end users (including seafarers, fishermen, recreational sailors) and nautical policy experts before being presented to OWF developers, and before licenses can be granted.

The Dutch approach to NRA is quite comprehensive and well-established. In terms of flexibility, it is not quite as flexible as that of the UK, but is certainly more on par with Germany's approach. Aside from 'traditional' NRAs, the consideration of ship manoeuvrability and minimum waterway width are factors which the Dutch have pursued more vigorously than other countries, in order to ensure that their sea space is used as safely and efficiently as possible. This is certainly an approach that can certainly be better integrated within NRA processes in other coastal states.

\subsubsection{Belgium}

Bordering two OWF 'giants' - the UK to the West and the Netherlands to the NorthBelgium also has some serious ambitions of its own when it comes to offshore wind. Despite only having a coastline of approximately $67 \mathrm{~km}$, Belgium has a COWC of 712 MW, which places it at the sixth rank globally. Currently, 182 OWTs are installed off the coast of Belgium - and the Belgium government has given approval for four more OWFs to be built in the future.

OWFs in Belgium need an environmental license which is granted by the Ministry of Public Health and Environment. The NRA is a part of this environmental license and is conducted by the OWF developer. The NRA is checked by Directorate-General Shipping, which is a part of the Federal Ministry of Transport, as well as by the Agency for Maritime and Coastal Affairs from the Flemish Region, who are responsible for pilotage and VTS in the whole of Belgium. 
The factors and stakeholders which are considered during a NRA in Belgium are very similar to those that are considered in other countries. There are particular similarities between the NRA process in Belgium and the Netherlands. Factors which are taken into consideration during a NRA in Belgium include, but are not limited to, vessel traffic, static and dynamic environmental conditions, and OWF-related information such as the location and layout of OWTs. Stakeholders who are consulted during a NRA in Belgium include seafarers and pilots, port and harbour authorities, ship owners, VTS operators and end users involved in emergency maritime operations, such as search and rescue (SAR).

A NRA in Belgium covers most maritime operations, including passing shipping traffic, WSV operations, installation and decommissioning operations, and emergency operations including SAR. Operations in ports and harbours that deal with OWF activities, however, are not covered as part of the NRA. The NRA only covers the installation and operation phases of an OWF, and not the decommissioning phase.

Belgian authorities do not require OWF developers to follow any specific methods for the NRA. They do, however, recommend the use of IMO's FSA framework, and MARIN's SAMSON model-although developers can opt for other models and tools with reasonable justification as well. ${ }^{12}$ Regardless of which model they use, at the very minimum, OWF developers should be able to demonstrate that they have assessed the probability of navigational accidents quantitatively. This requires a comparison of basecase and future-case scenarios, with and without an OWF, whilst accounting for factors such as vessel traffic, shipping routes, effect of OWTs on navigational equipment, weather conditions, hydrographic features, existing risk-control options and OWF layouts. Belgian authorities are particularly interested in the frequency of accidents before and after an OWF is installed, and base their decision heavily on this parameter, which is why they recommend a model like SAMSON.

There are no specific requirements with regard to consequence assessment in Belgium either - but it is strongly recommended that developers conduct quantitative probabilistic assessments which can estimate the likelihood and level of consequences in terms such as potential ship damage, expected OWF downtime, potential environmental damage and possible human casualties. Such quantitative consequence assessment can be conducted through SAMSON, if that model is being used.

Each OWF has its own specific impact on navigation, and subsequently, each NRA is judged on a case-by-case basis. There are no generic guidelines on how low the probability and/or consequences of navigational accidents need to be, and the acceptability criteria are determined on the back of the NRA and stakeholder consultations.

The Belgian approach to NRA is quite similar to the Dutch approach, which-given their shared borders, and close proximity of OWFs - works out very well according to the respondents from both Belgium and the Netherlands. Recently, Belgium and the Netherlands even submitted a joint FSA to the IMO to implement certain joint routing measures that would mitigate the risk of navigational accidents in the vicinity of OWFs. Despite the fact that Belgian authorities opt for $500 \mathrm{~m}$ safety distance between their shipping lanes and OWFs, whilst the Dutch opt for at least 1.87 NM, the joint proposal was quite a success. Although they may have different views of how 'safe' a system is, or what the acceptable distance between a shipping lane and an OWF should be, they

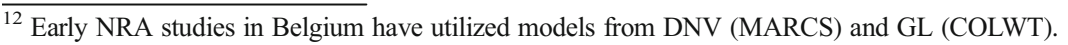


nonetheless have very similar, comparable NRA processes. Their joint approach is thus a perfect example that if countries wish to harmonize their NRAs, they can do so - and still have different opinions and acceptability criteria when it comes to navigational risk.

\subsubsection{Sweden}

Sweden can be classified as an 'emerging' nation when it comes to offshore wind energy generation. With just 86 installed OWTs, the Sweden has a COWC of $202 \mathrm{MW}$. Nevertheless, Sweden has ambitions to generate around $10 \mathrm{TWh}$ of energy from offshore wind by the year 2020 .

A NRA is necessary for OWFs in Sweden (BalticMaster 2007), where the licensing for such installations is carried out by the Environmental Court. The NRA is normally then checked by the Swedish Maritime Administration (Sjöfartsverket, or SMA for short) as well as the Swedish Transport Agency (Transportstyrelsen, or STA for short).

Despite being an 'emerging' nation in terms of offshore wind, Sweden has produced several comprehensive documents related to OWF NRA. The work of Ellis et al. (2008), for instance, was conducted to provide input for the Swedish NRA process. Following this work, a brief guidance document was produced by the governmental authorities (SMA and STA 2009). More recently, the Swedish Energy Agency (Energimyndigheten, or SEA for short), together with other relevant stakeholders such as SMA and STA, produced guidelines on health and safety issues related to OWFs (SEA 2014). Part of this guidance refers to safe navigation of vessels in the vicinity of OWFs. The factors and stakeholders which are considered during a NRA in Sweden are similar to those considered in other countries. The aforementioned documents identify vessel traffic, dynamic and static environmental conditions, OWF layout and location, and existing risk-control options including VTS, TSS, etc. as some of the factors that need to be considered during a NRA. When asked about the stakeholders, the interview respondents listed SMA, STA, the Environmental Court, Länsstyrelserna (county administrative boards), Havs- och Vattenmyndigheten (Swedish Agency for Marine and Water Management - SwAM) and various environmental organizations as some of the parties that need to be consulted during a NRA.

A NRA in Sweden should ideally assess the risk to all maritime operations including the risk to passing shipping traffic, the risk during WSV operations, the risk during OWF installation and decommissioning operations, the risk during emergency operations such as SAR in the vicinity of OWFs and even the risk during port and harbour operations related to OWFs. Subsequently a NRA should also be valid for the all phases of an OWF's life cycle-from installation, through operation, to decommissioning.

In Sweden, OWF developers are not required to use any specific models or methods for OWF NRA. That being said, the guidance document produced by SEA ( 2014) mentions the tool iWRAP-MK-II, which was developed by the International Association of Lighthouse Authorities (IALA). Traditionally, however, tools and models developed by the maritime consultancy SSPA (Ellis et al. 2008) are more commonly used for OWF NRA in Sweden than iWRAP; this is unsurprising considering that SSPA has played a major role in developing some of the guidelines related to OWF NRA in Sweden. SSPA's model for NRA is very similar to those developed by DNV, 
GL or MARIN - and also relies primarily on AIS data. Amongst other factors, the SSPA model takes into account vessel sizes and speeds, condition of the vessel (powered or drifting), layout of shipping routes, static and dynamic environmental conditions, OWF location and layout, and availability of risk-control options such as VTS, TSS or tugs, etc. Through this information, the model can quantitatively predict the probability of various navigational accidents in a given sea area both before and after an OWF is built. This information can also be combined with accident statistics to empirically quantify the probability and level of consequences.

Although it may not yet be a major OWF player, the existing NRA processes in Sweden reflect the country's ambitions for the future. Truly, Sweden is taking a proactive stance towards safety of navigation around OWFs.

\subsubsection{United States of America}

The last country considered in the present study is the US. The US, like Sweden, can be classified as an 'emerging' nation in terms of offshore wind energy generation. As of 2016, there is only one commercial OWF in the US - the five-turbine Block Island Wind Farm - giving the US a COWC of $30 \mathrm{MW}$. Yet, the US has great potential for OWF given their enormous coastlines along the Atlantic and Pacific seaboards, the Gulf Coast, the coast of Alaska, the Hawaii archipelago and the coasts of many of their outlying territories.

The Bureau of Ocean Energy Management (BOEM) is responsible for the licensing of all offshore renewable energy installations (OREIs) beyond 3 NM state waters; within the 3-NM limit, licensing of OWFs and other OREIs falls under the mandate of the US Army Corps of Engineers. A NRA is not required by law in either regime, but is generally included as part of the broader Environmental Review. The United States Coast Guard (USCG) is normally asked to weigh in on the NRA submissions.

Despite their late entry into the offshore wind sector, the US also has comprehensive documents with regard to NRA. In particular, the USCG has developed a thorough and comprehensive document pertaining to OREI NRA (USCG 2007). The document lists various factors - such as vessel traffic, ship types and sizes, waterway characteristics and static and dynamic environmental conditions including wind, waves, current and ice that should, amongst others, be accounted for during a NRA. The document also lists various stakeholders that need to be consulted during the NRA process. On a personal level, the interview respondent identified commercial seafarers, fishermen, recreational boaters, tug and barge operators, and various commercial shipping companies as important stakeholders to consider during the NRA. It is quite evident that the factors and stakeholders considered during a NRA in the US are similar to those considered in the other countries in the present study.

Developers in the US are encouraged to produce NRAs that assess the risk to all types of maritime operations - from passing vessel operations to WVS and installation and decommissioning vessel operations, as well as emergency maritime operations, and operations in ports and harbours that deal with OWF activities. The NRA should cover the installation and operation phases of an OWF's life cycle, but there is no specific requirement for a NRA to also cover the decommissioning phase.

As in several other countries, developers are not obliged or required to use any specific method, model or tool for NRA. Even though the guidance developed by the USCG mentions 'what-if analysis' as a tool, for example, it is simply a 
recommendation and not a requirement. Whilst there is no requirement to use any specific tools, it is important for OWF developers to demonstrate that they have considered all factors listed in the guidance document, some of which are mentioned above. Developers are also required to demonstrate the effect that their installation can have on the probability and consequences of navigational accidents, whilst accounting for each of the listed factors. In other words, developers are required to compare the base-case with possible future-case scenarios - a practice which is common in all of the countries considered in the present study.

Each OWF in the US is approved on a case-by-case basis, and as such, there are no generic guidelines about the probability or consequences being below a certain threshold. Generally, a stakeholder consultation may discuss the NRA results and decide whether the risks are acceptable or not.

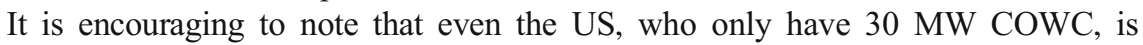
proactively addressing the navigational risk aspect of OWFs and OREIs.

\subsection{Exploring the gaps in existing NRA processes}

After describing the NRA process in their respective countries, the respondents were asked to indicate their agreement with ten statements, as shown in Table 5. The statements were derived through the literature review. By asking the respondents to rate these statements in an interview setting, the goal was to establish whether or not NRA experts (i.e. people who conduct or verify NRAs as part of their jobs) perceive these weaknesses as well — and, furthermore, to elicit their opinions on how they might wish to address these shortcomings.

\subsubsection{Statements 1, 2 and 3-harmonization of NRA processes}

One of the shortcomings identified by the literature review is a lack of harmonization between the NRA processes of different countries. Statements 1,2 and 3 in Table 5 relate to this particular concern. It is clear from both the literature review, and the descriptions provided by the respondents themselves, that NRA processes are not the same in different countries. The differences within the NRA processes of various countries, however, are quite subtle for the most part; in fact, it is evident that there are more similarities in the way that certain countries conduct NRAs. Belgium and the Netherlands, for instance, both recommend the same model for probability and consequence assessment; the UK, Denmark and the Netherlands all advocate the use of the FSA methodology; and the factors and stakeholders which are consulted during a NRA are identical across all the countries in the present study. Even the different commercial models used for probability and consequence assessment have some similarities in terms of calculation methods and input data- but subtle differences do exist, and may lead to significantly different NRA results.

The similarities are nonetheless a positive indicator, because the respondents unanimously agree (or strongly agree) with statement 1 - i.e. that the planning and approval of OWFs can be improved by harmonizing the steps of the NRA process. In particular, several of the respondents explicitly stated that having similar (or even the same) probability and consequence calculation process would be immensely useful - especially when it comes to transnational OWFs. This would help to avoid unexpected situations 
Table 5 Agreement ratings assigned to different statements by the respondents

\begin{tabular}{|c|c|c|c|c|c|c|c|}
\hline & $\begin{array}{l}5156 \mathrm{MW} \\
\mathrm{UK}\end{array}$ & $\begin{array}{l}4108 \mathrm{MW} \\
\mathrm{DE}\end{array}$ & $\begin{array}{l}1271 \mathrm{MW} \\
\mathrm{DK}\end{array}$ & $\begin{array}{l}1118 \mathrm{MW} \\
\mathrm{NL}\end{array}$ & $\begin{array}{l}712 \mathrm{MW} \\
\mathrm{BE}\end{array}$ & $\begin{array}{l}202 \mathrm{MW} \\
\mathrm{SE}\end{array}$ & $\begin{array}{l}30 \mathrm{MW} \\
\mathrm{US}\end{array}$ \\
\hline $\begin{array}{l}\text { 1. The planning/approval of } \\
\text { OWFs (especially } \\
\text { trans-national OWFs) can be } \\
\text { improved by harmonizing } \\
\text { the steps of the NRA pro- } \\
\text { cess in different countries }\end{array}$ & A & A & A & SA & SA & A & A \\
\hline $\begin{array}{l}\text { 2. All countries should have the } \\
\text { same NRA process for } \\
\text { offshore wind farms } \\
\text { (OWFs) }\end{array}$ & A & A & A & A & A & NAD & NAD \\
\hline $\begin{array}{l}\text { 3. A step-by-step best practice } \\
\text { guide for OWF NRA should } \\
\text { be produced by an intergov- } \\
\text { ernmental organization } \\
\text { (such as the IMO) to ensure } \\
\text { a harmonized NRA process } \\
\text { across different countries }\end{array}$ & A & NAD & NAD & A & A & A & NAD \\
\hline $\begin{array}{l}\text { 4. There is a need to improve } \\
\text { the transparency of the NRA } \\
\text { process in terms of the } \\
\text { models and data that are } \\
\text { used }\end{array}$ & $\mathrm{D}$ & NAD & A & A & A & A & $\mathrm{D}$ \\
\hline $\begin{array}{l}\text { 5. There is a need to improve } \\
\text { the input data that is used in } \\
\text { NRA frameworks, methods } \\
\text { and models }\end{array}$ & NAD & NAD & NAD & A & NAD & A & NAD \\
\hline $\begin{array}{l}\text { 6. There is a need to improve } \\
\text { the models that are used } \\
\text { during the NRA process }\end{array}$ & $\mathrm{D}$ & NAD & NAD & A & D & A & NAD \\
\hline $\begin{array}{l}\text { 7. There is a need to improve } \\
\text { the way through which } \\
\text { stakeholder feedback is } \\
\text { incorporated in the NRA } \\
\text { process }\end{array}$ & $\mathrm{D}$ & NAD & $\mathrm{D}$ & NAD & NAD & A & $\mathrm{D}$ \\
\hline $\begin{array}{l}\text { 8. The is a need to improve the } \\
\text { communication between } \\
\text { maritime and offshore } \\
\text { energy stakeholders during } \\
\text { the NRA process }\end{array}$ & $\mathrm{D}$ & NAD & NAD & $\mathrm{D}$ & NAD & A & A \\
\hline $\begin{array}{l}\text { 9. There is a need to improve } \\
\text { the communication of NRA } \\
\text { results to seafarers }\end{array}$ & $\mathrm{D}$ & NAD & $\mathrm{D}$ & $\mathrm{D}$ & SA & NAD & A \\
\hline $\begin{array}{l}\text { 10. Seafarers that operate near } \\
\text { OWFs should be provided } \\
\text { with risk-based decision } \\
\text { support systems that allow } \\
\text { them to assess navigational } \\
\text { risk operationally }\end{array}$ & A & NAD & $\mathrm{D}$ & $\mathrm{D}$ & A & NAD & NAD \\
\hline
\end{tabular}

$S A$ strongly agree, $A$ agree, $N A D$ neither agree nor disagree, $D$ disagree, $S D$ strongly disagree

wherein the probability and consequences of navigational accidents are calculated differently for the same OWF, as was the case with Krieger's Flak-which is an OWF that jointly lies in the EEZs of Sweden, Denmark and Germany (Ellis et al. 2008). 
It should be mentioned that the two countries that 'strongly agree' with statement 1 - BE and NL — already have a very harmonized process: they recommend the same process and the use of the same model for probability and consequence calculations (SAMSON) - and consider very similar factors and consult very similar stakeholders during the NRA. These two countries have also made joint submissions to the IMO for routing measures near their shared OWF boundaries. At the same time, they have different views of risk-acceptability - e.g. how much safe distance should be maintained between an OWF boundary and a shipping route. Nonetheless, their experience of harmonization seems very positive and mutually beneficial. As mentioned earlier, this case clearly shows that harmonization can be achieved while still having different opinions and risk-acceptance criteria.

Statement 2 did not garner the same unanimity as statement 1 from the respondents of the two emerging OWF nations: while the respondents of the US and Sweden agree with the need to harmonize steps within the NRA process, they are unsure about whether all countries should have the exact same NRA process. Their primary concern is the implementation challenge of such a measure. This is understandable from their point of view: they do not currently have as much stake in offshore wind as other countries, and for them, the bureaucratic burden of revamping their entire process to match the others far outweighs the potential benefits; the Swedish respondents particularly view having the same process as a generally unfeasible endeavour. These respondents also feel that regional approaches might be better rather than international harmonization. Nevertheless, the respondent from the US mentioned the potential benefits of having 'international guidance' that can augment the NRA process in the country.

This ties in with statement 3, which was designed to ask respondents about who should take the lead for the harmonization of the NRA process - and whether it should be a top-down initiative led by the IMO, for instance, or if a more bottom-up approach led by various member states would be more preferable. The responses indicate a preference for the top-down approach — with four of the seven respondents agreeing and three indicating neutrality.

The respondents with a neutral stance on statement 3 have reservations about the practicality of a top-down approach, and/or the ability of organizations like IMO to push through such standards in a reasonable time. These reservations are not entirely unfound either ${ }^{13}$ : while IMO has pushed through globally accepted regulations, it is undeniably true that this process can take a very long time; a good recent example of this is the Ballast Water Management Convention-which took 14 years to just being adopted in 2004, and another 13 years to finally enter into force in 2017. Furthermore, there are many technical guidelines - e.g. on ship manoeuvrability standards, which are still not ratified by all member states. Despite these shortcomings, $\mathrm{IMO}^{14}$ should strive

\footnotetext{
${ }^{13}$ When the IMO started its work in 1958, initially, it was forced to develop international legal instruments following a number of maritime accidents that occurred at that time. As a result, the early work of the IMO has often been portrayed as more reactive in its nature. After almost 65 years of successful work allowing the international legal instruments developed in IMO to demonstrate their positive effects, it is clear that this approach has changed and IMO has adopted a more pro-active approach in respect to maritime safety.

${ }^{14}$ The perceived 'role' of IMO is quite interesting when it comes to OWFs. A study by Gibson and Howsam (2010), which plotted various stakeholders on an interest-influence graph placed IMO in the bottom-left quadrant - i.e. IMO is perceived to have a low interest, and low influence in matters related to the approval of OWFs.
} 
to work together with member states who have experience with OWFs, to publish guidance documents on NRA. If done right, this would surely be welcomed by other member states, as it could help to provide clarity and coherence in an age where seascapes are increasingly cluttered.

Instead of opting for an international approach through IMO, an alternative approach to statement 3 would be if member states with OWFs formed regional agreements to harmonize their NRA processes. In fact, North Sea countries - who incidentally have the most experience with OWFs - have just recently signed a political declaration ${ }^{15}$ that includes harmonization as of its core objectives. This provides a precedent for other countries to undertake similar measures at a regional level.

\subsubsection{Statements 4, 5 and 6-transparency and adequacy of models and input data}

The second main shortcoming of NRA processes, as identified through the literature review, is the apparent lack of transparency when it comes to the models and input data that are used in these processes. The agreement ratings assigned to statements 4, 5 and 6 indicate a very split view of this perceived shortcoming. Unlike the harmonization concern - where there was near unanimity - agreement towards this second shortcoming seems to be influenced much more by the personal perceptions and opinions of the individual respondents.

When asked whether there is a need to improve the transparency of models and input data (statement 4), respondents from both the UK and US disagreed, the respondents from Germany indicated neutrality, whilst the respondents from the other 4 countries agreed. Respondents from the UK and the US believe that their NRA process is transparent enough - and that the models and input data which are used by the respondents are openly available for scrutiny. Therefore, they do not see the need to improve further - but nevertheless mention that they are open to suggestions for further improvements. The transparency of the NRA process - in the UK particularly - is undeniably exemplar: it is, for instance, quite easy to find correspondence between the MCA (or other stakeholders) in the UK and the consultative bodies that perform NRAs on behalf of OWF developers asking for clarification with certain aspects of the models, input data or assumptions (NIP 2017).

It is also very encouraging to see that $\mathrm{DK}, \mathrm{NL}, \mathrm{BE}$ and $\mathrm{SE}$ themselves see the need to improve the accessibility of their already-quite-transparent NRA processes. While these other countries also strive for transparency, they are evidently not yet at the level of the UK in this matter. Part of this may be due to the language 'barrier': NRA studies, and even guidance documents, or documents describing the models and input data from these countries are not always available in English (or not available at all); this means that third-party interested stakeholders may have a harder time accessing and evaluating these documents, or recreating and validating NRA results (Ellis et al. 2008). This is not to say that all countries should conduct NRAs in English - but rather a request to the authorities to ensure that at least the core documents are accessible by all stakeholders. Shipping is truly a global industry, and while OWFs may be 'locally' placed, they can have an influence on a much broader spectrum of stakeholders than just local

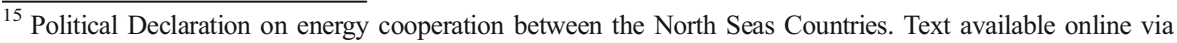
https://ec.europa.eu/energy/
} 
folks. Most countries already issue 'notices to mariners' in English, and it would be very helpful if documents describing NRA models were also made available in such a manner to ensure a transparent process.

Statement 5 asked respondents if there is a need to improve the input data that is used during the NRA process. While NL and SE indicated their agreement, five of seven respondents indicated a neutral stance to statement 5. This statement is clearly very hard to judge. As mentioned in the literature review section, OWFs are still a 'new' development - and a lot of the input data used for OWF NRA is merely derivative from navigational risk studies for oil platforms, bridges, quays, piers and other offshore installations. Even though OWFs have now been around for almost a quarter of a century, and our understanding of the navigational risks associated with such installation is much improved, there are still gaps in specific knowledge. The input data used so far has been quite effective in helping to avert navigational accidents. At the same time, as the respondents from Sweden highlighted, a lot of the data used in NRA processes stem from accidents statistics - but there have not been enough accidents to create a reliable dataset. This means it is still too early to say if our present knowledge, assumptions and data are good enough, especially when considering the predicted evolution of the offshore wind sector over the coming years and the possible increased impact that this might have on navigational safety.

Due to this cyclical development, the respondents with a neutral outlook to statement 5 appear to have opted for a cautious 'time-will-tell' attitude. Naturally, as the offshore wind sector evolves, more and more data will also become available - which will hopefully lead to an improved understanding of navigational risks associated with OWFs. One can question, however, whether a 'wait-and-see' approach is prudent. Powerful modelling tools and simulators - which incidentally are recommended, and even used as part of the NRA process in the UK and NL-are becoming increasingly common and feasible. Simulators can allow users to create 'future-case' scenarios and explore navigational behaviour and challenges in a more proactive manner-giving access to scenario-specific data and allowing the validity of assumptions to be thoroughly tested (Mehdi et al. 2017b). Approval authorities may thus benefit greatly by advocating further use of such technology.

This leads us to statement 6-which asked respondents whether there is a need to improve the models that are used to calculate the probability and consequences of navigational accidents within the NRA processes. Statement 6 had quite polarized responses - with NL and SE agreeing, UK and BE disagreeing, and the other three countries opting for a neutral stance. The respondents who disagree with, or rate this statement neutrally, are of the opinion that there is no need to improve the models further, as the existing ones have done an adequate job at preventing navigational accidents around OWFs; these respondents nevertheless indicated their openness to new innovations, and stated that they would gladly adapt new models and tools, if they were demonstrably better than the existing ones. Respondents from NL and SE opt for a more proactive approach, and clearly state that they would like to continually improve the models that they use during their NRAs-irrespective of whether or not there is a need.

There is merit in both viewpoints. It is undoubtedly more effective and efficient for all approval authorities and developers alike (in fact, for all stakeholders involved in NRA) to stick with the tried-and-tested models. At the same time, the current and 
predicted evolution of the offshore wind sector serves as an ominous reminder against complacency, and highlights the need to be proactive with NRA models: it is not enough to have models that help to prevent accidents for now; NRA models should be robust enough to allow for the safe and efficient planning of increasingly complex and crowded marine areas in the future.

When discussing statement 6 , it is also important to highlight that researchers have developed, applied and validated some excellent tools and models (Deeb et al. 2017; Mehdi and Schröder-Hinrichs 2016) — which definitely are on par with, if not better than, some commercially available tools. Unfortunately, many of the research models are underused in real-world applications. This is certainly not the fault of any particular stakeholder group - approval authorities, for example, are very open to developers using new tools and models as long as they are valid and comply with recommendations or guidelines; academics are eager to promote their work; and commercial organizations are happy to work with research organizations in improving their own models or collaboratively developing new ones. Why then is it that the maritime industry always appears to be slow in adapting these state-of-the-art tools? There is not a definitive answer, but respondents indicated that two factors may play a major role: comfort and lack of awareness. Most OWF developers and consultative agencies are comfortable using the most convenient and popular models - even if they do not perform at the level of more complex models; it is also a hassle to continually use new models instead of sticking with a 'trusted' one, which is also an understandable issue. The lack of awareness, meanwhile, stems from the issue that sometimes researchers often fail to show the value of their work (language barriers, publication barriers, poor communication, etc.). Together, these two factors may be a reason why some cuttingedge navigational models have not seen much use in industry yet.

\subsubsection{Statements 7, 8, 9 and 10-stakeholder communication within the NRA process}

The last possible shortcoming in the existing NRA process, as identified by the literature review, pertains to stakeholder communication. Statement 7 , therefore, directly asked the respondents if there is a need to improve the way in which stakeholder feedback is incorporated in the NRA process. Respondents from the UK, DK and US disagreed, whilst the respondents from DE, NL and BE indicated their neutrality. Only the respondents from SE agreed with this statement. The respondents who disagreed with this statement were of the opinion that stakeholder consultations in their countries are already quite robust, and pointed towards ample communication loops and workshops, wherein stakeholders are encouraged to express their viewpoints. It was also pointed out that it may be impossible to please all stakeholders - which might be why there are occasional complaints about feedback not being taken into account. In reality, the comments from each stakeholder are well-documented and thoroughly considered by the approval authorities, and efforts are made to find the best possible compromise where necessary.

It is noteworthy that the respondents from SE agree with statement 7. The number of agencies and stakeholders that are involved in the NRA in Sweden is comparatively higher than other countries - and may explain this sentiment. This may mean it is more difficult to incorporate stakeholder feedback compared to other countries. One can expect, however, that as the offshore sector evolves in Sweden, so too will the stakeholder consultation process. 
The respondents were also asked if there is a need to improve the communication between the maritime and offshore wind industry stakeholders, via statement 8 . This particular limitation of NRA processes cannot be explicitly identified in any literature-but given the technical and specialized nature of the NRA, and wind turbine/farm design processes, the authors wanted to identify whether approval authorities would like to see more cooperation between the shipping and offshore wind industries. The researchers expected the respondents to be polarized on this issue: it can be argued that the maritime and offshore wind energy stakeholders only need to the know information that is relevant to them-and not necessarily understand the intimate technical details underlying each other's work; on the other hand, one can also make the case that a better mutual understanding of navigational risks and wind turbine/farm design may lead to better cooperation amongst stakeholders, as well as more effective use of sea space.

As expected, there was no unanimous agreement between the respondents on statement 8. The respondents from the UK and NL disagreed with this statement, and stated that they felt that the communication between these two groups of stakeholders is adequate in their countries. Respondents from SE and the US, meanwhile, agreed with statement 8 - whilst respondents from the other three countries neither agreed nor disagreed.

There was a very interesting discussion with the respondent from BE on statement 8 . Stakeholders from the energy industry often assume that ships only sail along wellplanned routes and follow routing measures as shown on spatial plans or nautical charts, as shown in Fig. 1 for the Belgian EEZ. In reality, ships have absolute freedom of navigation under $\mathrm{UNCLOS}^{16}$ - and vessels, particularly fishing boats and pleasure crafts, often also sail outside corridors that are reserved for shipping, as shown in Fig. 2 for the Belgian EEZ. In fact, some vessels may regularly sail in areas that are specifically designated for OWFs on a spatial plan (where an OWF has yet to be approved)-but developers may not realize this until they submit their plans for approval because they are not familiar with maritime operations.

If an OWF is planned solely on the basis of nautical charts and spatial plans, without due consideration of actual shipping traffic, it can lead to unwarranted issues during the approval stages: in such scenarios, NRA studies may recommend more stringent risk-control options than usual to mitigate the higher-thananticipated navigational risk. Such stringent safety measures can, in turn, potentially reduce the efficiency of maritime operations, by-for instanceforcing ships to take longer routes around OWFs; subsequently, these measures may be seen as unwelcome cost burdens by maritime stakeholders. In some cases, the OWF developers may also be required to pay more than they anticipated for the implementation of risk-control options such as collisionfenders, or markings and lightings on turbines. In extreme cases, OWFs may have to be redesigned in the interest of navigational safety. In fact, the respondent from $\mathrm{BE}$ highlighted a case where a row of turbines had to be

\footnotetext{
${ }^{16}$ The exception to this is areas that are specifically designated as being mandatorily off limits for ships by a coastal state and/or IMO; such areas are generally only enforceable after an OWF has been granted approval or, in some cases, after the turbines have been installed.
} 


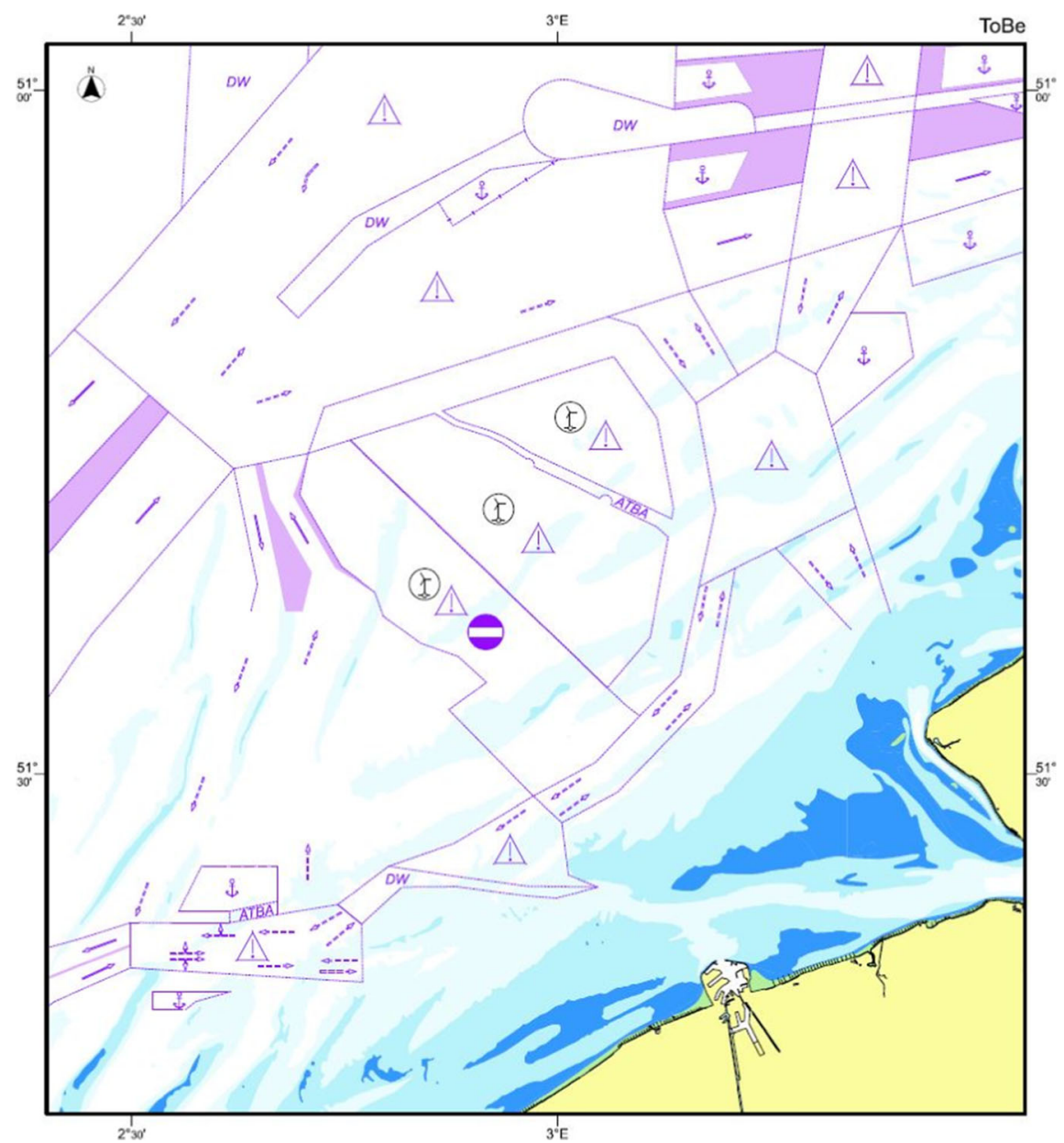

Fig. 1 Spatial plan of the Belgian EEZ. Source: authors

eliminated before the OWF was approved. This is clearly not an ideal situation for OWF developers, nor for maritime stakeholders.

From the above discussion, it is apparent that while communication between maritime and offshore wind energy stakeholders may be adequate during the approval stages, this may not necessarily be the case during the planning stages. If - as recommended by the respondent from BE in relation to statement 8 - there is improved communication between the two sectors during the planning stage as well, unexpected and costly 'surprises' might be reduced during the subsequent approval process.

Statement 9 asked respondents if there is a need to improve the communication of NRA results to operational end users who operate near OWFs - particularly seafarers. Respondents from the UK, DK and NL disagree with this statement. They believe that the NRA process - while open to feedback from seafarers - is not intended to provide any information to seafarers, but is merely a tool for decision makers to approve or deny the application for an OWF. The respondents for UK, DK and NL further point to 


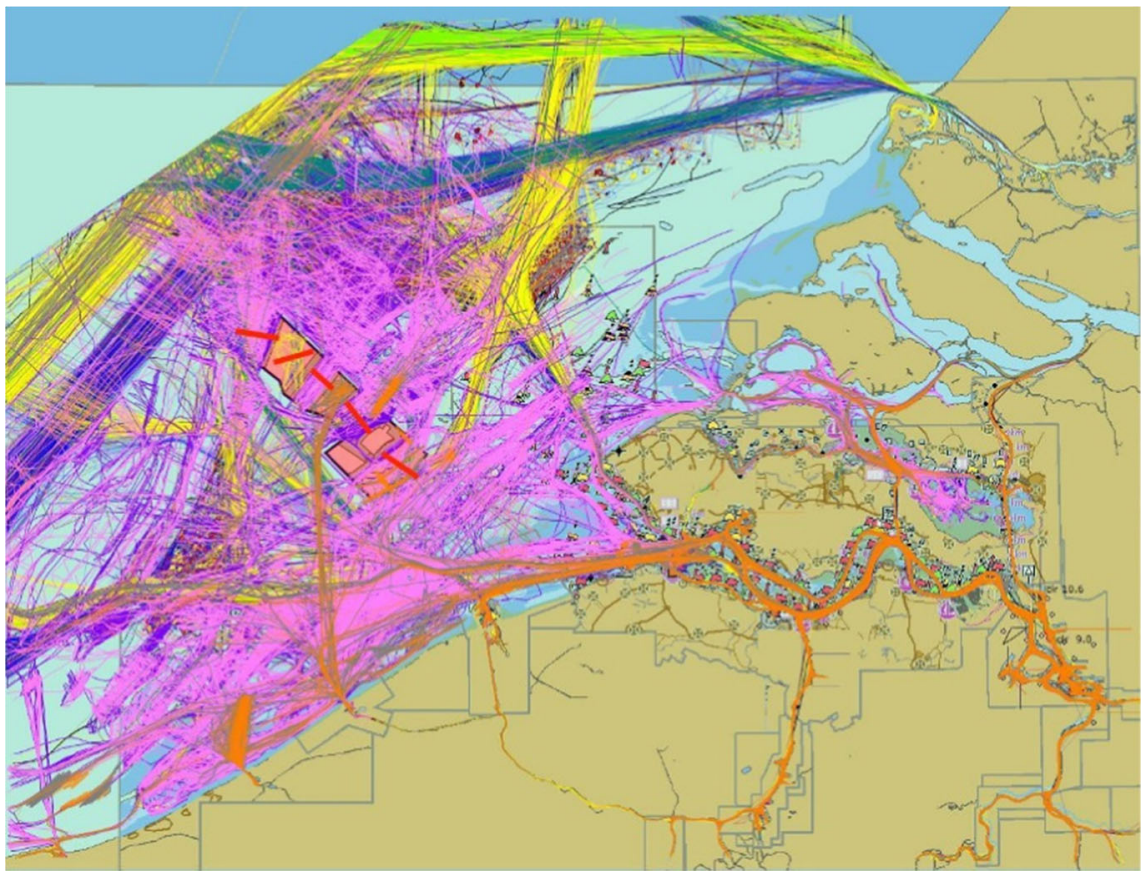

Fig. 2 Actual ship movements in the Belgian EEZ, mapped using AIS data. Source: EMSA (European Maritime Safety Agency)

the measures such as notice to mariners, which, they say, provide the relevant information to operational end users including seafarers.

By contrast, the respondents from the US and BE agree and strongly agree with statement 9. The respondent from BE particularly felt that the direct results of the NRA process should be more open and accessible to seafarers - and that they should not only be used as feedback providers. Belgium has quite a small, crowded EEZ, which poses severe spatial challenges - so much so that authorities often struggle to find adequate space between OWFs and shipping lanes. The respondent from BE believes that seafarers being more aware of the direct results of NRAs is therefore quite important.

It was mentioned earlier that a survey found seafarers who are aware of NRA studies tend to be more concerned about navigational risks than seafarers who are not (Mehdi et al. 2017a). One reason for this was suggested to be that seafarers are asked for feedback, but not necessarily communicated the results of the NRA process. In particular, some of the seafarers who were critical of the NRA process stated:

- 'I did not get results feedback' [on an unidentified North Sea OWF]

- 'Only aware of the study as it [sic...result] was not promulgated' [on the London Array]

- 'I was deeply disappointed as I expressed my concerns and have not even been contacted to explain reasons why my concerns where not addressed' [on an OWF near Liverpool—possibly Burbo Bank] 
The above statements from seafarers are perhaps a sign that the communication of NRA results to seafarers does need be improved further.

This leads to statement 10, which asked the respondents if seafarers should be provided with decision support tools when operating near OWFs. The respondent from $\mathrm{BE}$, unsurprisingly agreed with this statement - as did the respondent from the UK. Respondents from DK and NL disagreed, while those from the other three countries neither agreed nor disagreed with this statement.

The respondents that disagree with statement 10 cite their concerns that seafarers may be overloaded with information; these respondents believe that prudent seafarers already make adequate decisions by performing thorough situational awareness, and that existing information provisions and tools are enough. Those that agree with statement 10, meanwhile, say the seafarers need such information to operate near OWFs safely - and that regardless of risk-control options, the ultimate barrier to avoiding accidents are seafarers themselves. This latter group of respondents who advocate the provision of decision-support tools and information say that seafarers can use these tools if needed, or ignore it if they find them to be irrelevant. In other words, it is better to 'have' and 'not need' than to 'need' and 'not have'.

It is clear that the level of agreement towards statements 7, 8,9 and 10 is also significantly dependent on the personal perceptions of the various respondents - and highlights the need for stakeholders (particular OWF approval and licensing authorities) from different countries to come together, share their experiences and discuss these issues which are not sufficiently addressed in existing works.

\section{Conclusions}

Through a literature review and an interview study, the present work summarizes the NRA processes for OWFs in seven different countries. The interview study is also novel in identifying potential shortcomings in these NRA processes. The respondents, near-unanimously, agree that there needs to be harmonization between the NRA processes of different countries. There is, however, little consensus on some of the other issues, such as the transparency of models used for NRAs, or stakeholder communication.

\subsection{Recommendations}

Based on the findings of the study, the authors present the following list of recommendations and final thoughts:

\subsubsection{Harmonization of NRA processes between countries, and within countries between planning and approval stages}

The NRA processes of different countries should be harmonized. In particular, the calculation methods, factors and data sources used for probability and consequence calculations should be similar, especially across countries in close proximity to each other. This will help to avoid problems in approving transnational OWFs - and if done right, encourage further growth of the offshore sector by reducing the bureaucratic 
burden on OWF developers. It would also reduce the chances of transnational OWFs being approved in one country and being denied approval in another.

The NRA process is already quite similar in most countries, in terms of the factors that are considered and the stakeholders that are consulted. This means that harmonization is not as farfetched as cynics think it might be.

Methods and models used for probability and consequence calculations are also pretty similar (but not the same) in most countries; the exception is the consequence calculation process in Germany, where authorities seek quantitative proof of 'collision-friendly' design of turbines. Generally speaking, the calculation of accident probability in NRA always considers shipping traffic using AIS data, whereas the consequence calculations consider the typical mass and speeds (i.e. the kinetic energy) of vessels. If the processes are to be harmonized further, the authors recommend combining the consequence-assessment approach of Germany with probabilistic tools used by Belgium and the Netherlands. Thus far, most riskcontrol options have been focussed on reducing the probability of accidents, but as the offshore wind sector continues to evolve, accidents may become inevitable; it is thus prudent to understand the consequences of navigational accidents in more detail, and promote measures such as 'collision-friendly' design on at least the outermost turbines.

Harmonization does not mean that all countries or all OWFs should have the same acceptability criteria. Each country should still approve OWFs individually, based on what their approval authorities and local society perceive to be acceptable levels of probability and consequences. Harmonization also does not mean that the risk-control options implemented around OWFs to maintain navigational safety need to be the same: e.g. countries should still be able to have different safe-passing distances between shipping lanes and OWFs. Harmonization simply means having the same steps and calculation methods for processes such as probability or consequence assessments, to minimize discrepancies between countries as much as possible.

The IMO - based, for instance, on the experience of the North Sea countriesshould produce guidelines for probability and consequence calculation methods, stakeholder consultation, etc. as they have done for accident investigation or FSA. Ultimately, however, the implementation of the harmonization process should be led by the countries themselves on a regional level; this would help to ensure that countries around specific sea-basins (e.g. Baltic, Mediterranean or North Sea) have common interpretations of the harmonized NRA process guidelines during the implementation and application phase. A regional implementation approach for harmonized NRA process should also promote further communication and collaboration during the NRA process, and allow countries to share experiences from mutual topics and issues. Having comprehensive and thorough guidelines in place, and learning lessons from evolving and established countries, is a path that should be followed by all emerging nations especially, who have ambitious offshore energy plans.

It is also important to harmonize the NRA processes within the different countries. As mentioned by the respondent from Belgium, it is possible to have discrepancies between the planning and approval stages, which may mean that OWFs-asplanned are not OWFs-as-approved. This is where the Dutch and Belgian 
approaches clearly have an advantage. In the Netherlands, the federal authorities themselves conduct a NRA and present the results to developers for strict adherence-which means that the NRA is often the same through the planning to the approval stages. In Belgium, developers are recommended to use the same tools, methods and models for NRAs during the approval phases as the authorities use for NRAs during planning phases, in order to minimize discrepancies.

\subsubsection{Improving transparency, input data and tools used for NRA}

Due to lack of consensus amongst the respondents, the authors cannot conclusively state whether there is a need for more transparency, or if the models or input data need to be improved further. Instead, the authors recommend that various countries share the experiences in these matters through forums such as IMO working groups, or regional platforms such as the Political Declaration on energy cooperation between the North Seas Countries. In particular, countries that are satisfied with their processes should share guidelines and 'lessons-learnt' with countries that feel the need to improve their own NRA processes.

Promoting harmonization (see Section 5.1.1) can also indirectly lead to greater transparency of models and input data: decision makers could scrutinize the calculation methods and parameters much more closely before deciding on which model or tool to advocate in any joint-standard.

Academia and industry stakeholders (particularly approval authorities, OWF developers and NRA consultants) should work together to ensure that the best possible methods, models and tools are used for NRA. Most national guidelines are flexible and allow developers to use the tools of their choice as long as they cover all the required factors. However, developers and consultative bodies should move out of their comfort zone, and academics should promote their work better-as improved models could lead to significantly help to reduce over- and under-design for safety.

\subsubsection{Improving stakeholder communication}

There is also no consensus amongst the respondents on whether stakeholder communication needs to be improved. As with recommendation 2, the authors suggest a sharing-of-experiences, and discussions between countries.

Although some might disagree, the authors advocate improving the communication of the NRA results to seafarers, and also feel that decision-support systems should be made available (but not necessarily mandatory). This, in our opinion, would be a step further than current Notices to Mariners. Having such decision support systems could even help to alleviate some of the burden on planning and approval authorities, and allow more effective use of sea space. Instead of having fixed and expensive risk-control options (e.g. safety distances), for instance, decision support systems, on board ships and in VTS centres for instance, can provide more bespoke solutions for seafarers operating near OWFs, whilst accounting for 'live' dynamic and static environmental conditions.

All these recommendations have the potential to reduce the administrative load on OWF developers - but also more importantly, to significantly improve the planning and 
approval process of OWFs. This in turn can lead to more effective use of sea space, and allow marine spatial planners as well as approval authorities to find the right balance between navigational safety, efficiency and exploitation of space for energy generation.

\subsection{Future work}

The current work shows that despite a very good start, there is still a lot to be done when it comes to NRA processes for OWFs. This is especially the case for countries that are just now starting to develop an offshore wind portfolio. The potential for offshore wind energy generation is immense all across the globe, and countries that wish to exploit this resource would do well to follow in the footsteps of the North Sea countries.

In terms of research, the authors will further explore how each of the above recommendations can be implemented in practice. In doing so, the NRA processes in other countries with OWFs will also be analysed. Another important future task will be to gather the perspectives of OWF owners and developers, as well as the opinions of international regulatory bodies on the subject matter. Perhaps most importantly, future research will focus on producing harmonized steps for the NRA process that can also be integrated with other tools such as energy yield calculators and ship emission models; this may allow for more effective decision making over use of sea space.

Given the need for more renewable energy and the sheer benefits of offshore wind on one hand - and the importance of shipping and maritime activities on the other-it is vital that the two industries learn to coexist sooner, rather than later. This is easier said than done, given the predicted evolution and ambition of both industries - but certainly not impossible. And it will surely require the combined efforts of academics and maritime and offshore energy stakeholders to truly achieve this goal of coexistence.

To conclude this discussion on the coexistence of the maritime and offshore wind industries, perhaps the reader is best left with the words of Augustus William Hare:

'Thought is the wind, knowledge the sail, and mankind the vessel'.

Acknowledgements This research was supported by a Marie Curie Initial Training Network Grant within the 7th European Community Framework Programme. The authors of this work gratefully acknowledge support for this research under the project No. 309395 MARE-WINT provided by the EU.

This work was also supported by the Interreg North Sea Region European Regional Development Fund under the project NorthSEE (project no. 38-2-2-15).

The authors also would like to sincerely thank various partners from the NorthSEE project for helping to set up the interviews with the country respondents. Most of all, the authors would like to thank the respondents for investing time and effort to participate in this study. This study is dedicated to all offshore wind energy and maritime stakeholders who work tirelessly to ensure the coexistence of the two industries.

\section{Compliance with ethical standards}

Disclaimer The responses to the survey were provided by various individuals, and may not necessarily reflect the views of their colleagues or their organization. The agreement ratings assigned to various statements, in particular, are based on the personal opinion and perceptions of the individual respondentsand do not reflect the official standpoint of any organization. 


\section{References}

[AP] Associated Press (2018) Global wind turbine market growth, trends, and forecasts to 2023ResearchAndMarkets.com. Available via newsok.com. Accessed 13th May 2018

[BMVI] Federal Ministry of Transport and Digital Infrastructure (2014a) Offshore Windenergie Sicherheitsrahmen-konzept (OWE-SRK). German Federal Ministry of Transport and Digital Infrastructure, Berlin

[BMVI] Federal Ministry of Transport and Digital Infrastructure (2014b) Durchführungsrichtlinie, seeraumbeo-bachtung offshore-windparks. German Federal Ministry of Transport and Digital Infrastructure, Berlin

[BSH] Federal Maritime and Hydrographic Agency (2015) Minimum requirements concerning the constructive design of offshore structures within the Exclusive Economic Zone (EEZ). German Federal Maritime and Hydrographic Agency, Hamburg

[DEA] Danish Energy Agency (2017) Danish experiences from offshore wind development. Danish Energy Agency, Copenhagen

[GDWS] Directorate-General for Waterways and Shipping (2014a) Rahmenvorgaben zur Gewährleistung der fachgerechten Umsetzung verkehrstechnischer Auflagen im Umfeld von Offshore-Anlagen hier: Kennzeichnung. Kiel: German Directorate-General for Waterways and Shipping

[GDWS] Directorate-General for Waterways and Shipping (2014b) Richtlinie, ffshore-Anlagen“ zur Gewährleistung der Sicherheit und Leichtigkeit des Schiffsverkehrs Version 2.0. Kiel: German Directorate-general for waterways and shipping.

[GL] Germanischer Lloyd (2002) Richtlinie zur Erstellung von technischen Risikoanalysen für OffshoreWindparks. Selbstverlag des Germanischer Lloyd. Hamburg, Germanischer Lloyd SE

[GL] Germanischer Lloyd (2008) Offshore Windparks - Wirksamkeit kollisionsverhindernder Maßnahmen. Abschluß-bericht. Bericht-Nr: NER 2008.178 Version 1.8/2008-11-24. Hamburg, Germanischer Lloyd SE

[GWEC] Global Wind Energy Council (2016) Global wind report: annual market update 2015. Global Wind Energy Council, Brussels

[IEMA] Institute of Environmental Management and Assessment (2004) Guidelines for environmental impact assessment. Lincoln, Institute of Environmental Management and Assessment

[IMO] International Maritime Organization (2002) Guidelines for formal safety assessment (FSA) for use in the IMO rule-making process (as amended). MSC/Circ.1023, MEPC/Circ.392. London: International Maritime Organization

[IMO] International Maritime Organization (2012) Routing of ships, ship reporting and related matters. Report on the safety assessments for the proposed route structure on the North Sea off the coast of the Netherlands. NAV 58/INF. 2. London: International Maritime Organization

[MCA] Maritime and Coastguard Agency (2013) Methodology for assessing the marine navigational safety and emergency response risks of offshore renewable energy installations (OREI). Maritime and Coastguard Agency, Southampton

[MCA] Maritime and Coastguard Agency (2016) MGN 543 (M+F) safety of navigation: offshore renewable energy installations (OREIs) - UK navigational practice, safety and emergency response. Maritime and Coastguard Agency, Southampton

[MIA] The Ministry of Infrastructure and the Environment, [MEA] The Ministry of Economic Affairs (2014) White Paper on off shore wind energy partial review of the national water plan Holland coast and area north of the Wadden Islands. Rijksoverheid, The Hague

[NIP] National Infrastructure Planning (2017) [internet]. Bristol: Planning Inspectorate. c2012-2017 [cited 2017 Jan 02]. Available from: https://infrastructure.planninginspectorate.gov.uk/projects/

[SCBD] Secretariat of the Convention on Biological Diversity (2005) Handbook of the convention on biological diversity including its Cartagena protocol on biosafety, 3rd edn. Friesen, Montreal

[SEA] Swedish Energy Agency (2014) Vindkraft - Arbetsmiljö och säkerhet. Energimyndigheten, Bromma

[SMA] Swedish Maritime Administration, [STA] Swedish Transport Agency (2009) Vägledning vid projektering och riskanalys av vindkraftsetableringar utmed svesnka kusten. Sjöfartsverket, Norrköping

[USCG] United States Coast Guard (2007) Guidance on the coast guard's roles and responsibilities for offshore renewable energy installations (OREI). COMDTPUB P16700.4, NVIC 02-07. Washington DC, United States Coast Guard

Anatec (2017) COLLRISK [internet]. Aberdeen: Anatec UK Ltd; [cited 2017 May 6]. About 1 Screen Available from: https://www.anatec.com/products/collrisk

Andersson MH (2011) Offshore wind farms - ecological effects of noise and habitat alteration on fish [dissertation]. Stockholm University, Stockholm 
Bailey H, Brookes KL, Thompson PM (2014) Assessing environmental impacts of offshore wind farms: lessons learned and recommendations for the future. Aquat Biosyst 10:8

BalticMaster (2007) Offshore windfarm development and the issue of maritime safety. Case study "Kriegers Flak” I, II and III [internet]. Karlskrona: Region Blekinge; [cited 2017 May 6]. 46 p. Available from: http:/www.balticmaster.org/media/files/general_files_713.pdf

Beiersdorf A, Radecke A (2014) Ecological research at the offshore windfarm alpha ventus : challenges, results and perspectives. Springer, Wiesbaden

Bela A, Le Sourne H, Buldgen L, Rigo P (2017) Ship collision analysis on offshore wind turbine monopile foundations. Mar Struct 51:220-241

Biehl F, Lehmann E (2006) Collisions of ships with offshore wind turbines - calculation and risk evaluation. In: Köller J, Köppel J, Peters W (eds) Offshore wind energy: research on environmental impacts. Springer, Heidelberg, pp 281-304

Blanco MI (2009) The economics of wind energy. Renew Sust Energ Rev 13:1372-1382

Bray L, Reizopoulou S, Voukouvalas E, Soukissian T, Alomar C, Vázquez-Luis M et al (2016) Expected effects of offshore wind farms on Mediterranean marine life. J Mar Sci Eng 4(1):18

Chen J-L, Liu H-H, Chuang C-T, Lu H-J (2015) The factors affecting stakeholders' acceptance of offshore wind farms along the western coast of Taiwan: evidence from stakeholders' perceptions. Ocean Coast Manag 109:40-50

Chircop A, L'Esperance P (2016) Functional interactions and maritime regulation: the mutual accommodation of offshore wind farms and international navigation and shipping. Ocean Yearbook 30:439-487

de la Vega D, Matthews JCG, Norin L, Angulo I (2013) Mitigation techniques to reduce the impact of wind turbines on radar services. Energies 6:2859-2873

Deeb H, Mehdi RA, Hahn A (2017) A review of damage assessment models in the maritime domain. Ships Offshore Struc 12(S1):31-54

Degraer S, Brabant R (eds) (2009) Offshore wind farms in the Belgian part of the North Sea: state of the art after two years of environmental monitoring. Brussels: Royal Belgian Institute for Natural Sciences, Management Unit of the North Sea Mathematical Models. Marine ecosystem management unit

Desholm M, Kahlert J (2005) Avian collision risk at an offshore wind farm. Biol Lett 1(3):296-298

Devine-Wright P (2005) Beyond NIMBYism: towards an integrated framework for understanding public perceptions of wind energy. Wind Energy 8:125-139

Dierschke V, Garthe S, Mendel B (2006) Possible conflicts between offshore wind farms and seabirds in the German sectors of North Sea and Baltic Sea. In: Köller J, Köppel J, Peters W (eds) Offshore wind energy: research on environmental impacts. Springer, Heidelberg, pp 121-143

Ellis J, Forsman B, Huffmeier J, Johansson J (2008) Methodology for assessing risks to ship traffic from offshore wind farms. VINDPILOT-Report to Vattenfall AB \& Swedish Energy Agency. Göteborg, SSPA Sweden AB

Engie.be (2017) In Europe, offshore wind energy is following in the path of onshore wind energy. Available via www.engie.be/en. Accessed 13th May 2018

Gibson E, Howsam P (2010) The legal framework for offshore wind farms: a critical analysis of the consents process. Energy Policy 38:4692-4702

Haggett C (2008) Over the sea and far away? A consideration of the planning, politics and public perception of offshore wind farms. J Environ Policy Plan 10(3):289-306. https://doi.org/10.1080/15239080802242787

Hattam C, Hooper T, Beaumont N (2015) Public perceptions of offshore wind farms. Plymouth Marine Laboratory on behalf of The Crown Estate, Plymouth ISBN: 978-1-906410-66-7

Henderson AR, Morgan C, Smith B, Sørensen HC, Barthelmie RJ, Boesmans B (2003) Offshore wind energy in Europe - a review of the state-of-the-art. Wind Energy 6(1):35-52. https://doi.org/10.1002/we.82

Hüppop O, Dierschke J, Exo K-M, Fredrich E, Bird Migration HR (2006) Offshore wind turbines. In: Köller J, Köppel J, Peters W (eds) Offshore wind energy: research on environmental impacts. Springer, Heidelberg, pp 91-116

Köller J, Köppel J, Peters W (eds) (2006) Offshore wind energy: research on environmental impacts. Springer, Heidelberg

Lacroix D, Pioch S (2011) The multi-use in wind farm projects: more conflicts or a win-win opportunity? Aquat Living Resour 24:129-135

Ladenburg J (2011) Attitude and acceptance of offshore wind farms - the influence of travel time and wind farm attributes. Renew Sust Energ Rev 15:4223-4235

Le Sourne H, Barrera A, Maliakel JB (2015) Numerical crashworthiness analysis of an offshore wind turbine jacket impacted by a ship. J Mar Sci Technol 23(5):694-704

Maegaard P, Krenz A, Palz W (2013a) Wind power for the world: the rise of modern wind energy: Pan Stanford Series on Renewable Energy, vol 2. CRC Press, Boca Raton 
Maegaard P, Krenz A, Palz W (2013b) Wind power for the world: international reviews and developments: Pan Stanford Series on Renewable Energy, vol 3. CRC Press, Boca Raton

MARICO (2007) Investigation of technical and operational effects on marine radar close to Kentish flats offshore wind farm. Southampton, Marine and Risk Consultants Limited

Mehdi RA, Schröder-Hinrichs J-UA (2016) Theoretical risk management framework for vessels operating near offshore wind farms. In: Ostachowicz W, McGugan M, Schröder-Hinrichs J-U, Luczak M (eds) MARE-WINT: new materials and reliability in offshore wind turbine technology. Springer, Cham, pp 359-400

Mehdi RA, Schröder-Hinrichs J-U (2018) Core concepts of risk safety \& reliability. Springer, Cham

Mehdi RA, Ostachowicz W, Luczak M (2016) Introduction. In: Ostachowicz W, McGugan M, SchröderHinrichs J-U, Luczak M (eds) MARE-WINT: new materials and reliability in offshore wind turbine technology. Springer, Cham, pp 1-9

Mehdi RA, Schröder-Hinrichs J-U, Baldauf M (2017a) A tale of two industries: seafarer perceptions of offshore wind farms. Submitted to Journal of International Maritime Safety, Environment Affairs and Shipping

Mehdi RA, Baldauf M, Dalaklis D, Schröder-Hinrichs JU (2017b) Making the case: simulators for offshore renewable energy installations navigational risk assessment. Proceedings of HumanSEA MARISK 5th International Symposium; 2016 Oct 3-4; Nantes, France, Gomylex, p. 169-88

New L, Bjerre E, Millsap B, Otto MC, Runge MC (2015) A collision risk model to predict avian fatalities at wind facilities: an example using golden eagles, Aquila chrysaetos. PLoS One 10(7):e0130978. https://doi.org/10.1371/journal.pone.0130978

Ostachowicz W, McGugan M, Schröder-Hinrichs J-U, Luczak M (eds) (2016) MARE-WINT: new materials and reliability in offshore wind turbine technology. Springer, Cham

Samoteskul K, Firestone J, Corbett J, Callahan J (2014) Changing vessel routes could significantly reduce the cost of future offshore wind projects. J Environ Manag 141:146-154

Siemens AG (2014) A macro-economic viewpoint: what is the real cost of offshore wind? Siemens AG Wind Power, Hamburg

Snyder B, Kaiser M (2009) Ecological and economic cost-benefit analysis of offshore wind energy. Renew Energ 34:1567-1578

Vagias WM (2006) Likert-type scale response anchors. Clemson University, Clemson

Van der Tak C (2010) Quantitative risk assessment for offshore wind farms in the North Sea. Report 23601.621/4. Wageningen, MARIN

Verfuss UK, Sparling CE, Arnot C, Judd A, Coyle M (2016) Review of offshore wind farm impact monitoring and mitigation with regard to marine mammals. In: Popper AN, Hawkins A (eds) The effects of noise on aquatic life II. Advances in experimental medicine and biology, vol 875. Springer, New York, pp 11751182

Wang Y, Sun T (2012) Life cycle assessment of CO2 emissions from wind power plants: methodology and case studies. Renew Energ 43:30-36

Weinzettel J, Reenaas M, Solli C, Hertwich EG (2009) Life cycle assessment of a floating offshore wind turbine. Renew Energ 34:742-747

WindEurope (2017) The European offshore wind industry-key trends and statistics 2016. WindEurope, Brussels

Wright G, Mehdi RA, Baldauf M (2016) 3-dimensional forward looking sonar: offshore wind farm applications. Proceedings of 2016 European Navigation Conference (ENC); 2016 May 30 - Jun 2; Helsinki, Finland. IEEE, p. 1-8 